ARTICLE

Check for updates

https://doi.org/10.1038/s41467-021-21852-7

\title{
Flexible and high-performance electrochromic devices enabled by self-assembled 2D $\mathrm{TiO}_{2} / \mathrm{MXene}$ heterostructures
}

Ran $\mathrm{Li}^{1,2,7}$, Xiaoyuan Ma (1) ${ }^{2,7}$, Jianmin $\mathrm{Li}^{1}$, Jun Cao (1) ${ }^{2}$, Hongze Gao ${ }^{3}$, Tianshu Li (1) ${ }^{3}$, Xiaoyu Zhang ${ }^{1}$, Lichao Wang ${ }^{1}$, Qinghong Zhang (1) ${ }^{1}$, Gang Wang ${ }^{1}$, Chengyi Hou (1) ${ }^{1}$, Yaogang Li ${ }^{1}$, Tomás Palacios ${ }^{4}$, Yuxuan Lin (iD) ${ }^{4,6 \times}$, Hongzhi Wang (i) ${ }^{1 凶} \&$ Xi Ling (1) $2,3,5 \bowtie$

Transition metal oxides (TMOs) are promising electrochromic (EC) materials for applications such as smart windows and displays, yet the challenge still exists to achieve good flexibility, high coloration efficiency and fast response simultaneously. MXenes (e.g. $\mathrm{Ti}_{3} \mathrm{C}_{2} \mathrm{~T}_{\mathrm{x}}$ ) and their derived TMOs (e.g. 2D $\mathrm{TiO}_{2}$ ) are good candidates for high-performance and flexible EC devices because of their $2 \mathrm{D}$ nature and the possibility of assembling them into loosely networked structures. Here we demonstrate flexible, fast, and high-coloration-efficiency EC devices based on self-assembled $2 \mathrm{D} \mathrm{TiO} / \mathrm{Ti}_{3} \mathrm{C}_{2} \mathrm{~T}_{x}$ heterostructures, with the $\mathrm{Ti}_{3} \mathrm{C}_{2} \mathrm{~T}_{x}$ layer as the transparent electrode, and the $2 \mathrm{D} \mathrm{TiO}_{2}$ layer as the $\mathrm{EC}$ layer. Benefiting from the wellbalanced porosity and connectivity of these assembled nanometer-thick heterostructures, they present fast and efficient ion and electron transport, as well as superior mechanical and electrochemical stability. We further demonstrate large-area flexible devices which could potentially be integrated onto curved and flexible surfaces for future ubiquitous electronics.

\footnotetext{
${ }^{1}$ State Key Laboratory for Modification of Chemical Fibers and Polymer Materials, College of Materials Science and Engineering, Donghua University, Shanghai, China. ${ }^{2}$ Department of Chemistry, Boston University, Boston, MA, USA. ${ }^{3}$ Division of Materials Science and Engineering, Boston University, Boston, MA, USA. ${ }^{4}$ Department of Electrical Engineering and Computer Science, Massachusetts Institute of Technology, Cambridge, MA, USA. ${ }^{5}$ The Photonics Center, Boston University, Boston, MA, USA. ${ }^{6}$ Present address: Department of Electrical Engineering and Computer Sciences, University of California,

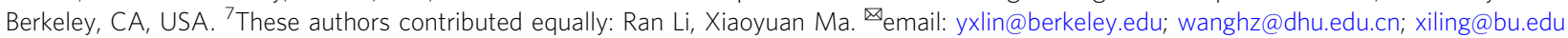


E lectrochromic (EC) materials, which can change their optical absorption reversibly due to the electrochemical redoxation with inserted ions under an applied potential ${ }^{1-3}$, have shown great promise in applications such as displays, smart windows and optical camouflage ${ }^{3-5}$. With the growing interest in bringing electrochromism to the field of flexible and wearable electronics in recent years, incorporating the functionality of flexibility to EC devices while maintaining high energy efficiency, fast switching speed and long durability has become increasingly critical $^{6,7}$. However, this is an extremely challenging task because: (a) both the EC performance and the mechanical properties are nontrivially correlated with the materials of choice, their nanoscale formations, and the assembly approach; and (b) the cooptimization of the transparent conductive electrode and the EC material, as well as the way to integrate them, are needed.

Recently, two-dimensional (2D) transition metal carbides, nitrides, and carbonitrides (referred to as MXenes) have emerged as promising nanoscale electronic materials with good electrochemical stability ${ }^{8,9}$. They have also been reported as promising templates for the synthesis of functional micro/nanostructured materials, such as transition metal oxides (TMOs), alkali-metal titanates, and their hybrids ${ }^{10,11}$. Owing to their unique optical and electrical properties, MXenes and their derivatives have demonstrated their potential in the application of energy storage, catalysis, and electronics ${ }^{12-14}$. More importantly, 2D nanosheets of both MXenes and their derivatives can be produced in liquid phase scalably, which makes it easy for constructing selfassembled films and hybrid structures, thus suitable for device applications in large scale.

We propose that self-assembled MXene/TMO heterostructures, with the MXenes as the flexible transparent electrode, and the TMOs (derived from the MXenes) as the flexible EC layer, are promising for high performance and flexible EC devices, yet it has never been explored previously. In addition to the advantage of the easiness of fabrication and integration with different functional components from MXene derivatives as mentioned above, an even more important reason is that the nanosheets network of TMOs, such as tungsten oxide $\left(\mathrm{WO}_{3}\right)$ and titanium oxide $\left(\mathrm{TiO}_{2}\right)$, can potentially realize not only superior EC properties, but also reliable mechanical and chemical stability among various candidates of EC materials. First, these inorganic materials are long-lasting and robust against environmental factors such as high temperature, ultraviolet radiation, and mechanical wear ${ }^{15-17}$, as compared to their organic counterparts ${ }^{18}$. Second, the nanostructured TMO network, especially in the form of $2 \mathrm{D}$ nanosheets, improves electrical and ionic transport significantly, because: (a) the increased surface-to-volume ratio of nanosheets as compared to the bulk forms leads to larger interface areas with the electrolyte and the shorter ion diffusivity pathways within the nanostructured channels; 3,15 and (b) the 2D formation of the nanostructures makes the contact area between adjacent nanosheets much larger than that between $1 \mathrm{D}$ or $0 \mathrm{D}$ structures (nanowires or quantum dots) ${ }^{19}$, which promotes the internanosheets electron transfer ${ }^{20}$. Finally, networks of $2 \mathrm{D}$ nanostructures also help to redistribute the induced strain evenly, thus improving both the mechanical strength and the flexibility of the film, which is fundamentally more advantageous than $1 \mathrm{D}$ or OD nanostructures for flexible devices ${ }^{21}$.

As a proof-of-concept demonstration, we successfully assemble $\mathrm{Ti}_{3} \mathrm{C}_{2} \mathrm{~T}_{\mathrm{x}}(\mathrm{T}=\mathrm{O}, \mathrm{OH}$, or $\mathrm{F})$ and the derived $\mathrm{TiO}_{2}$ nanosheets into uniform nanometer-thick films at a liquid-liquid interface, and fabricate EC devices based on the $\mathrm{TiO}_{2} / \mathrm{Ti}_{3} \mathrm{C}_{2} \mathrm{~T}_{\mathrm{x}}$ heterostructures on a flexible substrate. Due to the much improved ion diffusion and electron conductivity of assembled single-flake-layer $\mathrm{TiO}_{2}$ film and the $2 \mathrm{D}$ nature of both the MXene electrode and the $\mathrm{TiO}_{2}$ EC layer, our devices are among the best flexible EC devices with the fastest coloration speed, the highest coloration efficiency and superior electrochemical stability. We further demonstrate a large-area flexible device which could potentially be integrated with arbitrary curved and flexible surfaces for future ubiquitous electronics.

\section{Results}

Preparation of $2 \mathrm{D} \mathrm{TiO}_{2}$ via the chemical conversion from $\mathbf{T i}_{3} \mathbf{C}_{2} \mathbf{T}_{\mathbf{x}}$. Figure 1 illustrates the fabrication process of the selfassembled $\mathrm{TiO}_{2} / \mathrm{Ti}_{3} \mathrm{C}_{2} \mathrm{~T}_{\mathrm{x}}$ heterostructure on a flexible structure as the core functional component of EC devices. The fabrication process consists of three steps: First, the $\mathrm{Ti}_{3} \mathrm{C}_{2} \mathrm{~T}_{\mathrm{x}}$ nanosheet dispersion in deionized (DI) water is obtained from selective etching of $\mathrm{Ti}_{3} \mathrm{AlC}_{2}$ powder (MAX phase) ${ }^{22}$, and diluted to $0.2 \mathrm{mg} / \mathrm{L}$, followed by the formation of the $\mathrm{Ti}_{3} \mathrm{C}_{2} \mathrm{~T}_{\mathrm{x}}$ aerogel through freeze drying. The $\mathrm{Ti}_{3} \mathrm{C}_{2} \mathrm{~T}_{\mathrm{x}}$ aerogel is then annealed in air at $400{ }^{\circ} \mathrm{C}$ to fully be converted to the $\mathrm{TiO}_{2}$ aerogel; Second, the $\mathrm{Ti}_{3} \mathrm{C}_{2} \mathrm{~T}_{\mathrm{x}}$ $\left(\mathrm{TiO}_{2}\right)$ aerogels are dispersed into isopropyl alcohol (IPA) to form the $\mathrm{Ti}_{3} \mathrm{C}_{2} \mathrm{~T}_{\mathrm{x}}\left(\mathrm{TiO}_{2}\right)$ solutions, which are then injected into the interface between hexane and water, where the nanosheets selfassemble into uniform nanometer-thick films; Last, the selfassembled $\mathrm{Ti}_{3} \mathrm{C}_{2} \mathrm{~T}_{\mathrm{x}}$ film and $\mathrm{TiO}_{2}$ film are transferred sequentially onto a flexible polyethylene terephthalate (PET) substrate to form $\mathrm{TiO}_{2} / \mathrm{Ti}_{3} \mathrm{C}_{2} \mathrm{~T}_{\mathrm{x}}$ heterostructures, in which the $\mathrm{Ti}_{3} \mathrm{C}_{2} \mathrm{~T}_{\mathrm{x}}$ film serves as the transparent conductive electrode, and the $\mathrm{TiO}_{2}$ film serves as the EC layer in EC devices (more details about film assembly and transfer processes are in Supplementary Fig. 1, Supplementary Movie 1 and Supplementary Movie 2 in Supplementary Information).

To obtain the anatase phase of $\mathrm{TiO}_{2}$, which has been demonstrated a good EC material ${ }^{23}$, we anneal the $\mathrm{Ti}_{3} \mathrm{C}_{2} \mathrm{~T}_{\mathrm{x}}$ aerogel in air at $400{ }^{\circ} \mathrm{C}$ for $50 \mathrm{~h}$. X-ray diffraction (XRD) and Raman spectroscopy of the flakes are measured before and after the thermal annealing process to investigate the compositional and the structural changes. As shown in Fig. 2a, after annealing in air at $400^{\circ} \mathrm{C}$, new peaks at $26^{\circ}, 38^{\circ}, 48^{\circ}, 54^{\circ}$, and $63^{\circ}$ appear in the XRD spectra, corresponding to the (101), (112), (200), (105), and (204) planes of the anatase phase of $\mathrm{TiO}_{2}{ }^{24}$. Raman spectra of $\mathrm{Ti}_{3} \mathrm{C}_{2} \mathrm{~T}_{\mathrm{x}}$ flakes after annealing confirms the conversion from $\mathrm{Ti}_{3} \mathrm{C}_{2} \mathrm{~T}_{\mathrm{x}}$ to $\mathrm{TiO}_{2}$ (Fig. 2b), where peaks at $145 \mathrm{~cm}^{-1}\left(E_{\mathrm{g}}\right)$, $398 \mathrm{~cm}^{-1}\left(B_{1 \mathrm{~g}}\right), 518 \mathrm{~cm}^{-1}\left(B_{1 \mathrm{~g}}\right)$, and $639 \mathrm{~cm}^{-1}\left(E_{\mathrm{g}}\right)$ match well with the Raman features of the anatase phase of $\mathrm{TiO}_{2}{ }^{25}$. X-ray photoelectron spectroscopy (XPS) characterization further suggests the transformation from $\mathrm{Ti}_{3} \mathrm{C}_{2} \mathrm{~T}_{\mathrm{x}}$ to $\mathrm{TiO}_{2}$. It's clearly seen that the peaks for the $\mathrm{Ti}$ element in $\mathrm{Ti}_{3} \mathrm{C}_{2} \mathrm{~T}_{\mathrm{x}}$ (i.e., Ti-C $2 p_{3 / 2}$ (455.3 eV), Ti(II) $2 p_{3 / 2}(456.1 \mathrm{eV}), \mathrm{Ti}(\mathrm{III}) 2 p_{3 / 2}(457.2)$ ) disappear after the annealing (Fig. $2 c$ top and Supplementary Fig. 2), while peaks at $458.8 \mathrm{eV}$ and $464.8 \mathrm{eV}$, corresponding to $\mathrm{Ti}(\mathrm{IV}) 2 p_{3 / 2}$ and $\mathrm{Ti}(\mathrm{IV}) 2 p_{1 / 2}$ in $\mathrm{TiO}_{2}$, become dominant (Fig. $2 \mathrm{c}$ bottom) ${ }^{26}$.

To evaluate the morphology and crystallinity of the obtained $\mathrm{TiO}_{2}$ nanosheets, optical microscopy (OM), transmission electron microscopy (TEM) and atomic force microscopy (AFM) are used to characterize $\mathrm{Ti}_{3} \mathrm{C}_{2} \mathrm{~T}_{\mathrm{x}}$ flakes before and after the in situ conversion to $\mathrm{TiO}_{2}$. Supplementary Fig. 3 shows OM images of a typical flake $(\sim 7 \mu \mathrm{m}$ in lateral dimension) undergoing the annealing treatment at $400{ }^{\circ} \mathrm{C}$ for $50 \mathrm{~h}$, where the morphology of the flake maintains during the process. AFM images (Fig. 2d) show that the derived $\mathrm{TiO}_{2}$ flake remains the same shape as the $\mathrm{Ti}_{3} \mathrm{C}_{2} \mathrm{~T}_{\mathrm{x}}$ precursor. The surface roughness of the flake also does not change much after conversion (root mean square roughness changes from 514.3 to $528.2 \mathrm{pm}$ ). The thickness of the flake stays about $2 \mathrm{~nm}$ after being converted to $\mathrm{TiO}_{2}$. Typical TEM images (Fig. 2e and Supplementary Fig. 4) and selective area electron diffraction (SAED) patterns (insets of Supplementary Fig. 4) indicate that both $\mathrm{Ti}_{3} \mathrm{C}_{2} \mathrm{~T}_{\mathrm{x}}$ and $\mathrm{TiO}_{2}$ are in high crystallinity. 


\section{Step 1:}

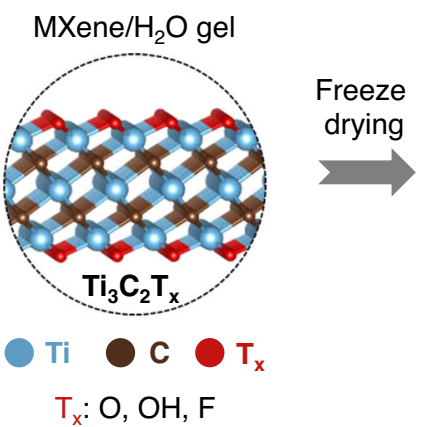

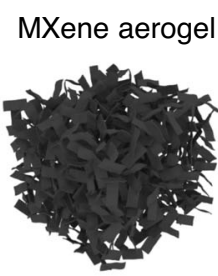

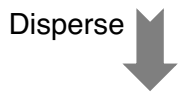

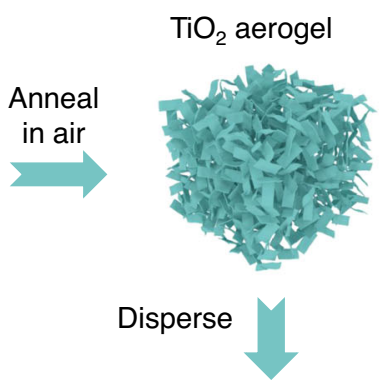

Step 2:
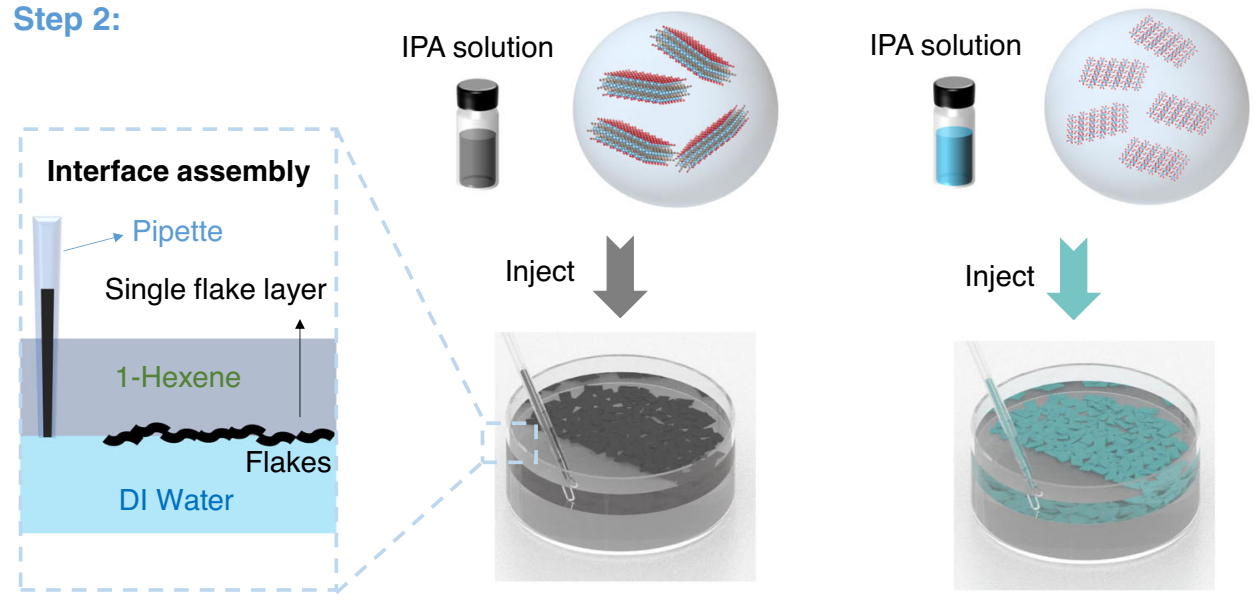

Inject
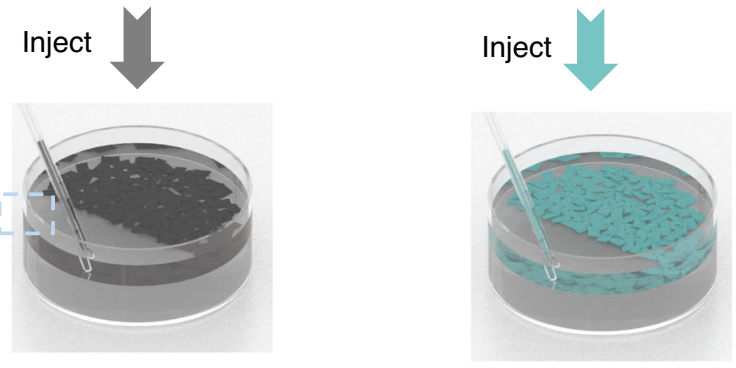

Step 3:

PET film

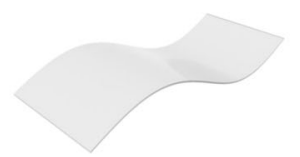

Transfer MXene/PET

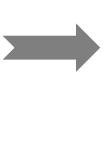

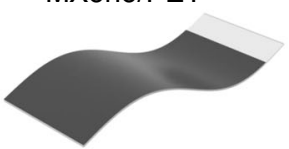

Transfer

$\mathrm{TiO}_{2} / \mathrm{MXene} / \mathrm{PET}$

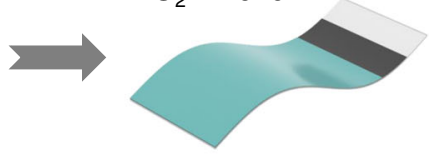

Fig. 1 Fabrication process of $\mathbf{T i O}_{2} / \mathrm{Ti}_{3} \mathbf{C}_{\mathbf{2}} \mathbf{T}_{\mathbf{x}}$ heterostructure on a flexible substrate. Step 1: MXene $\left(\mathrm{Ti}_{3} \mathrm{C}_{2} \mathrm{~T}_{\mathrm{x}}\right.$, crystal structures in the left panel, is drawn by Vesta software) aerogel is obtained by freeze drying of the $\mathrm{Ti}_{3} \mathrm{C}_{2} \mathrm{~T}_{x}$ nanosheets dispersion and the derived $\mathrm{TiO}_{2}$ aerogel is obtained by annealing the MXene aerogel in air at $400{ }^{\circ} \mathrm{C}$. Step 2: $\mathrm{Ti}_{3} \mathrm{C}_{2} \mathrm{~T}_{x}$ and $\mathrm{TiO}_{2} 2 \mathrm{D}$ nanosheets are dispersed, respectively, in IPA, injected into the interface between hexene and DI water, and self-assembled into nanometer-thick $\mathrm{Ti}_{3} \mathrm{C}_{2} \mathrm{~T}_{x}$ and $\mathrm{TiO}_{2}$ films. Step 3: the thin films are transferred onto a flexible substrate (e.g., $\mathrm{PET}$ ) in a layer-by-layer fashion to realize the $\mathrm{TiO}_{2} / \mathrm{MXene}$ heterostructure, where the $\mathrm{TiO}_{2}$ layer serves as the electrochromic component, and the $\mathrm{MXene}$ layer serves as the transparent electrode.

$\mathrm{Ti}_{3} \mathrm{C}_{2} \mathrm{~T}_{\mathrm{x}}$ shows a lattice spacing of $0.26 \mathrm{~nm}$, corresponding to its (100) plane. After annealing at $400{ }^{\circ} \mathrm{C}$, the derived $\mathrm{TiO}_{2}$ flake shows a lattice spacing of $0.27 \mathrm{~nm}$, which refers to the ${ }^{1-10}$ plane of the anatase phase of $\mathrm{TiO}_{2}$.

Moreover, when applying the conversion to the $\mathrm{Ti}_{3} \mathrm{C}_{2} \mathrm{~T}_{\mathrm{x}}$ aerogels, remained morphology is also observed after annealing at $400{ }^{\circ} \mathrm{C}$ to convert it to $\mathrm{TiO}_{2}$ (Supplementary Fig. 5). The pore size distribution in the $\mathrm{Ti}_{3} \mathrm{C}_{2} \mathrm{~T}_{\mathrm{x}}$ and $\mathrm{TiO}_{2}$ aerogels are similar (both have peaks at around $2 \mathrm{~nm}$ extracted from the nitrogen adsorption isotherm at 77K) (Supplementary Fig. 6). This result further suggests that the conversion reaction is confined on initial $2 \mathrm{D} \mathrm{Ti}_{3} \mathrm{C}_{2} \mathrm{~T}_{\mathrm{x}}$ flakes, leading to the good separation of each flake in the skeleton of aerogels during the conversion process.

Although the crystal lattice is transformed drastically from hexagonal $\left(\mathrm{Ti}_{3} \mathrm{C}_{2} \mathrm{~T}_{\mathrm{x}}\right)$ to tetragonal (anatase $\mathrm{TiO}_{2}$ ), our results clearly demonstrate the successful production of $\mathrm{Ti}_{3} \mathrm{C}_{2} \mathrm{~T}_{\mathrm{x}}$ flakes and their derived $\mathrm{TiO}_{2}$ flakes, both of which are high-quality crystals over micrometer large area with nanometer thin thicknesses. Based on these experimental results and comparing the crystal structures of $\mathrm{Ti}_{3} \mathrm{C}_{2} \mathrm{~T}_{\mathrm{x}}$ and the anatase phase $\mathrm{TiO}_{2}$, we propose the following mechanism to interpret the transformation from $\mathrm{Ti}_{3} \mathrm{C}_{2} \mathrm{~T}_{\mathrm{x}}$ to $\mathrm{TiO}_{2}$. As shown in Fig. $2 \mathrm{f}$, during the conversion, two $\mathrm{O}$ atoms need to replace one $\mathrm{C}$ atom sandwiched between two adjacent Ti layers. In this process, due to the gentle gas-solid reaction, the diffusion of $\mathrm{Ti}$ atoms is limited, and due to the similarity of the Ti frameworks in the $\mathrm{Ti}_{3} \mathrm{C}_{2} \mathrm{~T}_{\mathrm{x}}$ and $\mathrm{TiO}_{2}$ crystals, it does not require large rearrangement of $\mathrm{Ti}$ atoms during the conversion $^{27}$. Thus, the morphology of the flake can be retained.

Self-assembled ultrathin MXene films as high-performance transparent electrodes. To obtain large-area homogeneous thin films of the $\mathrm{TiO}_{2}$ or $\mathrm{Ti}_{3} \mathrm{C}_{2} \mathrm{~T}_{\mathrm{x}}$ network, a liquid/liquid interfacial self-assembly (LLIA) technique is used $^{28}$. Specifically, the $2 \mathrm{D}$ flakes/IPA dispersion is injected to the interface between hexane 
a

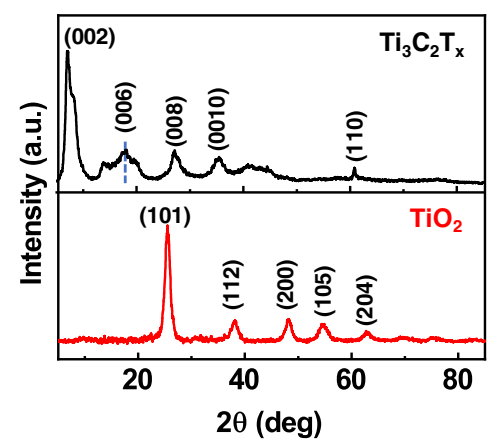

d

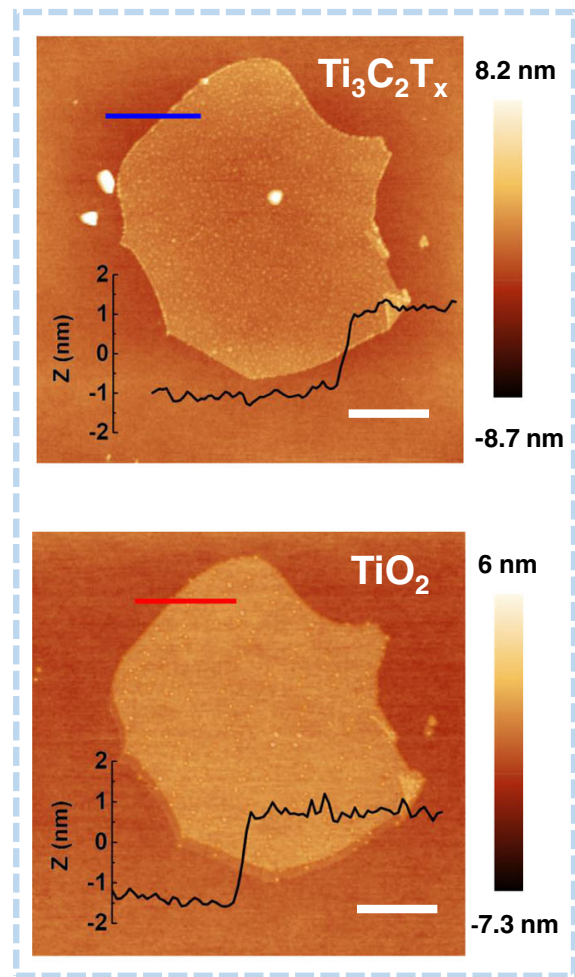

b

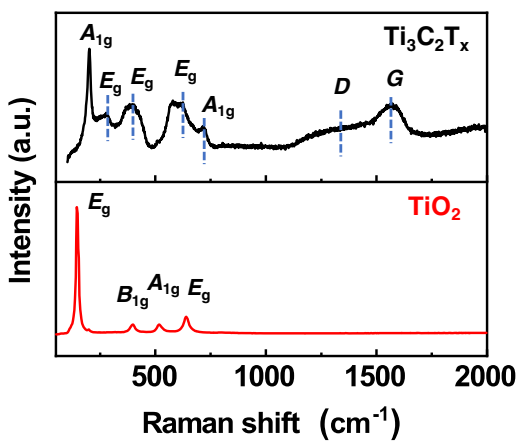

e

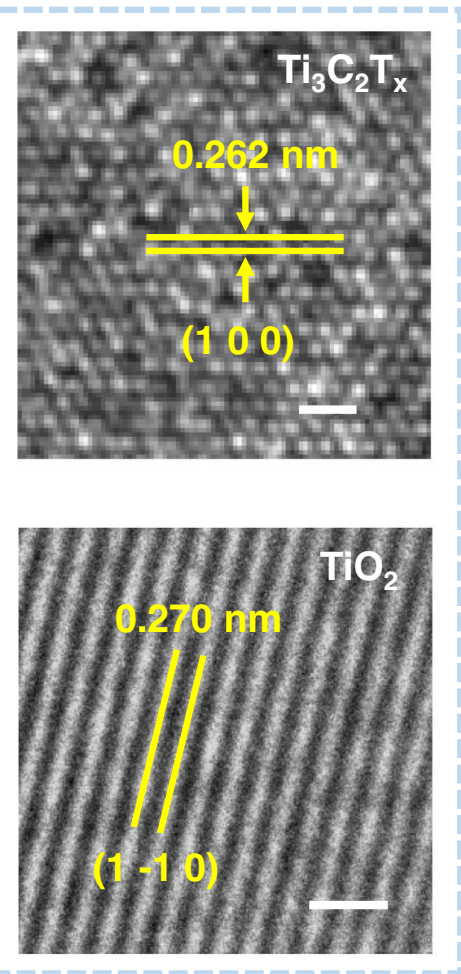

C

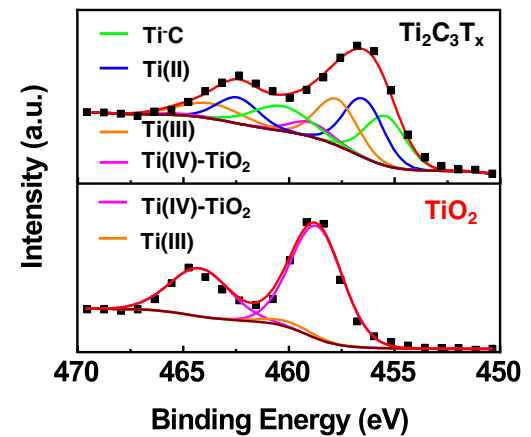

f

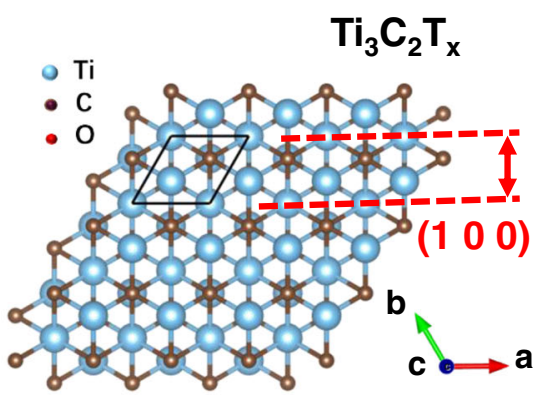

Fig. 2 Conversion of $\mathbf{T i}_{3} \mathbf{C}_{\mathbf{2}} \mathbf{T}_{\mathbf{x}}$ into $\mathbf{2 D} \mathbf{T i O}_{\mathbf{2}}$ flakes. a XRD patterns and $\mathbf{b}$ Raman spectra of the $\mathrm{Ti}_{3} \mathrm{C}_{2} \mathrm{~T}_{x}$ before and after annealing at $400{ }^{\circ} \mathrm{C}$ for $50 \mathrm{~h}$. $\mathbf{c} X P S$ spectra of the $\mathrm{Ti}_{3} \mathrm{C}_{2} \mathrm{~T}_{x}$ and the derived $\mathrm{TiO}_{2} ; \mathbf{d} \mathrm{AFM}$ images and height profiles of $\mathrm{Ti}_{3} \mathrm{C}_{2} \mathrm{~T}_{\mathrm{x}}$ and a derived $\mathrm{TiO}_{2}$ flake on a SiO${ }_{2} / \mathrm{Si}$ substrate (scale bar: $\left.2 \mu \mathrm{m}\right)$; e HRTEM images of $\mathrm{Ti}_{3} \mathrm{C}_{2} \mathrm{~T}_{x}$ and derived $\mathrm{TiO}_{2}$ flakes (scale bar: $1 \mathrm{~nm}$ ); $\mathbf{f}$ Crystal structures of $\mathrm{Ti}_{3} \mathrm{C}_{2} \mathrm{~T}_{\mathrm{x}}$ and derived anatase phase of $\mathrm{TiO}_{2}$.

and water. Because of the fast dissolution of IPA into the hexane layer, a surface tension gradient is established along the interface (Marangoni force $)^{29}$. Driving by this Marangoni force, the 2D flakes spreads out quickly and settles at the edge of the liquid interface, that is, either the sidewall of the container or the edge of an already assembled film. By optimizing the amount of the injected 2D flakes/IPA solution, a full coverage is achieved and a continuous $2 \mathrm{D}$ thin film is obtained. As shown in the OM image of Fig. 3a, the LLIA $\mathrm{Ti}_{3} \mathrm{C}_{2} \mathrm{~T}_{\mathrm{x}}$ film is homogeneous over a large area. According to the AFM image (Fig. $3 \mathrm{~b}$ and Supplementary Fig. 7) taken at the labeled area in Fig. $3 a$, the $\mathrm{Ti}_{3} \mathrm{C}_{2} \mathrm{~T}_{\mathrm{x}}$ flakes are all horizontally oriented, and placed next to each other with very small overlaps. This is very different from the films produced by the spray coating or spin coating methods where the orientations of the flakes are random, and they are mostly overlapped and bundled $^{30,31}$. To quantify the uniformity of the LLIA film in a large area, we extract the height profiles (Supplementary Fig. 7) from the AFM image, use it to calibrate the optical contrast of the OM image to obtain the thickness distribution over the area (Supplementary Fig. 8). The thickness distributions extracted from both the AFM image (small area) and the OM image (large area) are shown in Fig. 3c. It is observed that the peaks for both distributions appear at around $2 \mathrm{~nm}$, which corresponds to the thickness of 1-layer of $\mathrm{Ti}_{3} \mathrm{C}_{2} \mathrm{~T}_{\mathrm{x}}$ flake. The second most significant peak is at around $3.8 \mathrm{~nm}$, which corresponds to the overlapped area of two adjacent flakes (2 layers). These 1-layer and 2-layer regions are the key functional components for the electrical conductance, which covers $64 \%$ and $18 \%$ of the film, respectively.

Because of the uniform thickness distributions and the high coverage of 1-layer and 2-layer, the LLIA $\mathrm{Ti}_{3} \mathrm{C}_{2} \mathrm{~T}_{\mathrm{x}}$ films show both high optical transparency and high electrical conductance, making them ideal for the transparent electrodes of EC devices. The optical and electronic properties are evaluated by ultravioletvisible (UV-vis) spectrophotometry and a four-point probe 
a

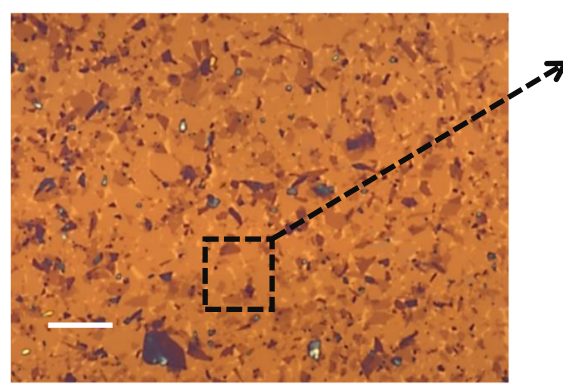

d

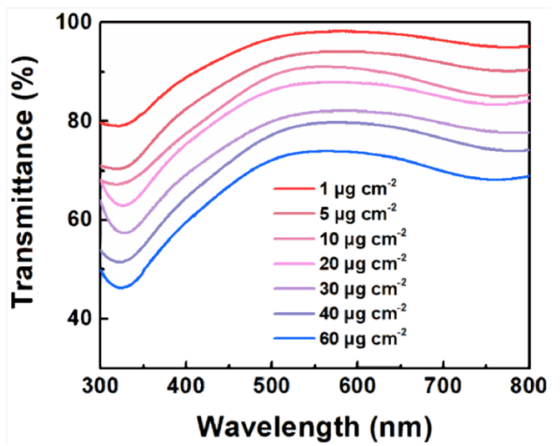

b

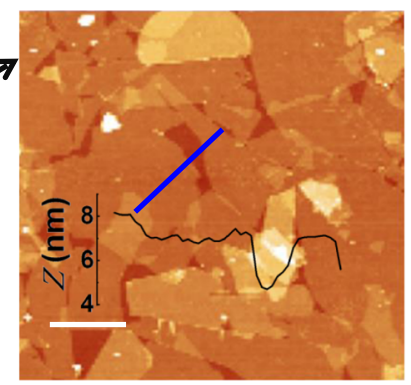

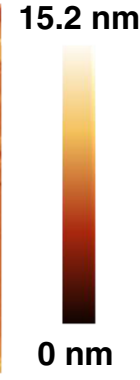

e

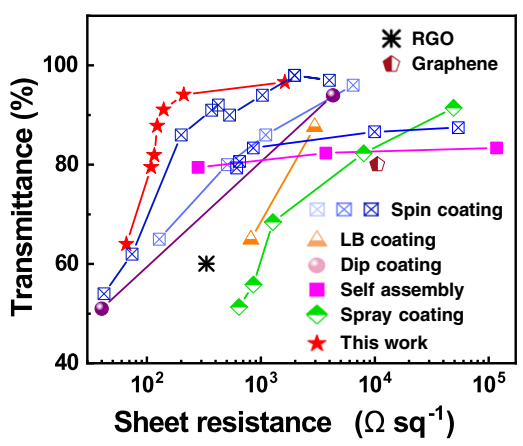

C

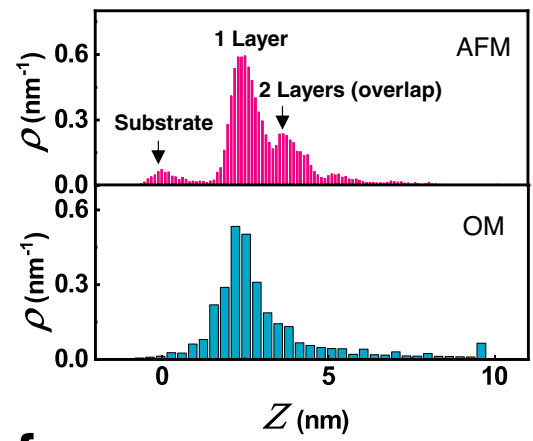

f

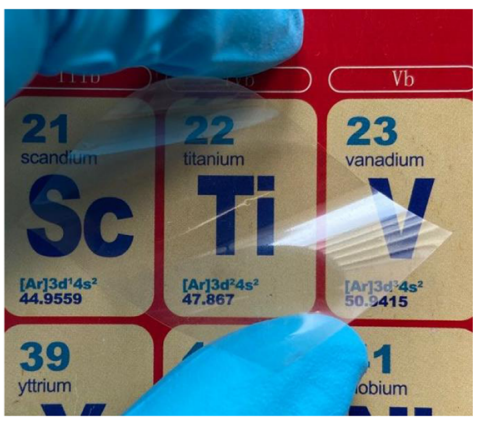

Fig. 3 Characterization of the self-assembled $\mathbf{T i}_{3} \mathbf{C}_{\mathbf{2}} \mathbf{T}_{\mathbf{x}}$ thin film as a transparent electrode. a OM image of the assembled Ti $\mathrm{C}_{2} \mathrm{~T}_{\mathrm{x}}$ thin film (scale bar: 10 $\mu \mathrm{m}) ; \mathbf{b}$ AFM image and the height profile of the assembled $\mathrm{Ti}_{3} \mathrm{C}_{2} \mathrm{~T}_{\mathbf{x}}$ thin film in corresponding area marked in $\mathbf{a}$ (scale bar: $2 \mu \mathrm{m}$ ). $\mathbf{c}$ Thickness distributions extracted from the AFM image (top) and the OM image (bottom); the $Y$-axes are probability density, namely, frequency per unit height; $\mathbf{d}$ Transmittance spectra of $\mathrm{Ti}_{3} \mathrm{C}_{2} \mathrm{~T}_{\mathrm{x}}$ films with various concentrations of injected $\mathrm{Ti}_{3} \mathrm{C}_{2} \mathrm{~T}_{\mathrm{x}}$; e Transmittance at 550 nm as a function of sheet resistance for the $\mathrm{Ti}_{3} \mathrm{C}_{2} \mathrm{~T}_{\mathrm{x}}$ films and data from previously reported transparent electrode technologies; $\mathrm{RGO}$ reduced graphene oxide, LB Langmuir-Blodgett. $\mathbf{f} \mathrm{Photograph}$ of a $\mathrm{Ti}_{3} \mathrm{C}_{2} \mathrm{Tx}$ film deposited on a PET substrate that presents excellent transparency and flexibility.

resistance measurement technique. The UV-vis spectra of these films with different $\mathrm{Ti}_{3} \mathrm{C}_{2} \mathrm{~T}_{\mathrm{x}}$ area concentrations are presented in Fig. $3 \mathrm{~d}$, where the area concentration is defined as the mass of $\mathrm{Ti}_{3} \mathrm{C}_{2} \mathrm{~T}_{\mathrm{x}}$ per square centimeter, and tuned by the volume of $2 \mathrm{mg} / \mathrm{ml} \mathrm{Ti}_{3} \mathrm{C}_{2} \mathrm{~T}_{\mathrm{x}}$ dispersion injected at the interface during the assembly. The transmittance of LLIA $\mathrm{Ti}_{3} \mathrm{C}_{2} \mathrm{~T}_{\mathrm{x}}$ at $550 \mathrm{~nm}$ reaches $96.8 \%$ when the area concentration is $1 \mu \mathrm{g} \mathrm{cm}^{-2}$, and decreases steadily to $64.3 \%$ as the area concentration increases to $60 \mu \mathrm{g} \mathrm{cm}^{-2}$ 32. The transmittance at $550 \mathrm{~nm}$ versus the sheet resistance $\left(R_{\mathrm{s}}\right)$ of the LLIA films, together with the data from previously reported techniques, are plotted in Fig. 3e. The $R_{\mathrm{s}}$ value of the LLIA $\mathrm{Ti}_{3} \mathrm{C}_{2} \mathrm{~T}_{\mathrm{x}}$ film reaches $1623 \Omega \mathrm{sq}^{-1}$ at a transmittance of $96.9 \%, 210 \Omega \mathrm{sq}^{-1}$ at $94.1 \%$, and $123 \Omega \mathrm{sq}^{-1}$ at $87.8 \%$. Comparing the resistances of materials with the similar transparency, our values are lower than MXene films made by other methods like spin coating (201 $\Omega \mathrm{sq}^{-1}$ at $\left.87 \%\right)$, dip coating (4300 $\Omega \mathrm{sq}^{-1}$ at $\left.94 \%\right)$, and spray coating (7974 $\Omega \mathrm{sq}^{-1}$ at $\left.82 \%\right)$, and also lower than other transparent conductive materials such as graphene, and reduced graphene oxide (see Supplementary Table 1 for a summary of different transparent conductive materials) ${ }^{30,31,33-40}$. Finally, Fig. $3 f$ shows that the LLIA $\mathrm{Ti}_{3} \mathrm{C}_{2} \mathrm{~T}_{\mathrm{x}}$ film can be transferred onto a flexible substrate (e.g., PET) uniformly in a large area $\left(\sim 25 \mathrm{~cm}^{2}\right)$ with excellent optical transparency, suitable for transparent conductive electrodes for the proposed flexible EC devices.

Fast and highly efficient electrochromism in $\mathrm{MXene} / \mathrm{TiO}_{2}$ heterostructures. The flexible $\mathrm{TiO}_{2} / \mathrm{Ti}_{3} \mathrm{C}_{2} \mathrm{~T}_{\mathrm{x}}$ heterostructure electrodes are fabricated by transferring LLIA $\mathrm{TiO}_{2}$ films on the $\mathrm{Ti}_{3} \mathrm{C}_{2} \mathrm{~T}_{\mathrm{x}} / \mathrm{PET}$ substrates. Similar to $\mathrm{Ti}_{3} \mathrm{C}_{2} \mathrm{~T}_{\mathrm{x}}, \mathrm{TiO}_{2}$ flakes in the
LLIA film also connect with each other to form a porous network, with the pore size in the range of nanometers, when observed under TEM and OM measurements (Supplementary Fig. 9 and Supplementary Fig. 10). The morphology of $\mathrm{TiO}_{2} / \mathrm{Ti}_{3} \mathrm{C}_{2} \mathrm{~T}_{\mathrm{x}}$ heterostructures are further characterized by OM, SEM, and AFM measurements. As shown in Fig. 4a, the boundary between the $\mathrm{TiO}_{2} / \mathrm{Ti}_{3} \mathrm{C}_{2} \mathrm{~T}_{\mathrm{x}}$ heterostructure and l-layer $\mathrm{TiO}_{2}$ film is clearly seen from the OM image. AFM characterization shows a thickness different of $\sim 2 \mathrm{~nm}$ across the boundary, matching well with the thickness of 1-layer $\mathrm{Ti}_{3} \mathrm{C}_{2} \mathrm{~T}_{\mathrm{x}}$, indicating a close contact between the $\mathrm{TiO}_{2}$ and $\mathrm{Ti}_{3} \mathrm{C}_{2} \mathrm{~T}_{\mathrm{x}}$ layers. Moreover, Supplementary Fig. 11 shows OM and SEM images of different layers (1, 4, and $7 \mathrm{~L}$ ) of LLIA $\mathrm{TiO}_{2}$ on $\mathrm{Ti}_{3} \mathrm{C}_{2} \mathrm{~T}_{\mathrm{x}}$ films, where the porous structures can be still seen in the stacked multiple layers.

The heterostructure provides a metal-semiconductor junction between $\mathrm{Ti}_{3} \mathrm{C}_{2} \mathrm{~T}_{\mathrm{x}}$ and $\mathrm{TiO}_{2}$, where $\mathrm{Ti}_{3} \mathrm{C}_{2} \mathrm{~T}_{\mathrm{x}}$ serves as the transparent electrode and $\mathrm{TiO}_{2}$ serves as the electrochromic layer. Note that $\mathrm{Ti}_{3} \mathrm{C}_{2} \mathrm{~T}_{\mathrm{x}}$ has a low work function $(1.6-4.4 \mathrm{eV})^{41,42}$, when comparing to other transparent electrodes, e.g. indium tin oxide (ITO, with the work function of $4.73 \mathrm{eV})^{43}$. When contacting with $\mathrm{TiO}_{2}$ (work function $\sim 4.2 \mathrm{eV}$ ), the Schottky barrier between $\mathrm{Ti}_{3} \mathrm{C}_{2} \mathrm{~T}_{\mathrm{x}}$ and $\mathrm{TiO}_{2}$ is much lower or it could even be an Ohmic contact ${ }^{44}$, compared to that between ITO and $\mathrm{TiO}_{2}$. Thus, the electron transport between the $\mathrm{Ti}_{3} \mathrm{C}_{2} \mathrm{~T}_{\mathrm{x}}$ and the $\mathrm{TiO}_{2}$ layer is expected to be greatly improved in the heterostructure.

Because of the well-controlled LLIA process, it is possible to regulate the EC properties simply by the thickness of the $\mathrm{TiO}_{2}$ layer. As shown in Figs. 4b, 1-5 layers of the LLIA $\mathrm{TiO}_{2}$ film are transferred sequentially onto a PET substrate in a layer-by-layer fashion. They are almost indistinguishable at the bleach state, 
a

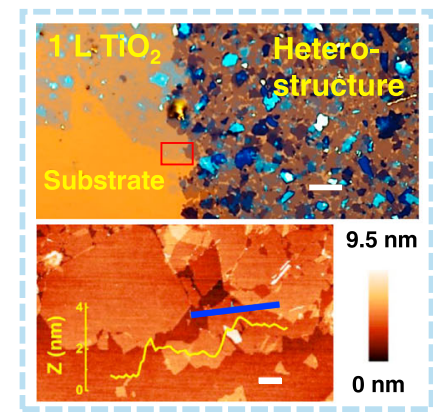

d

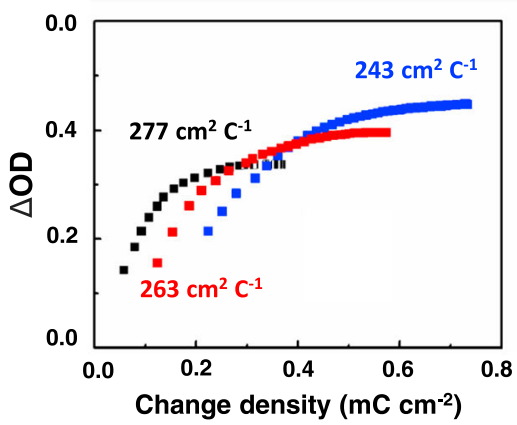

g

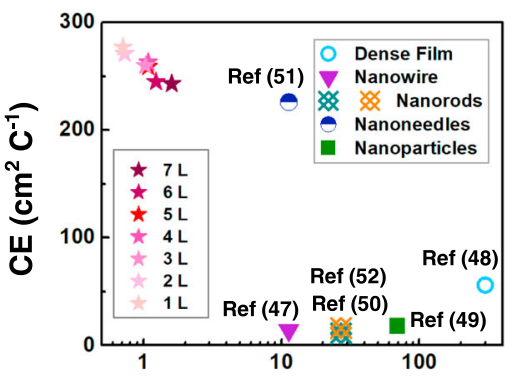

$\tau_{\mathrm{c}}(\mathbf{s})$ b

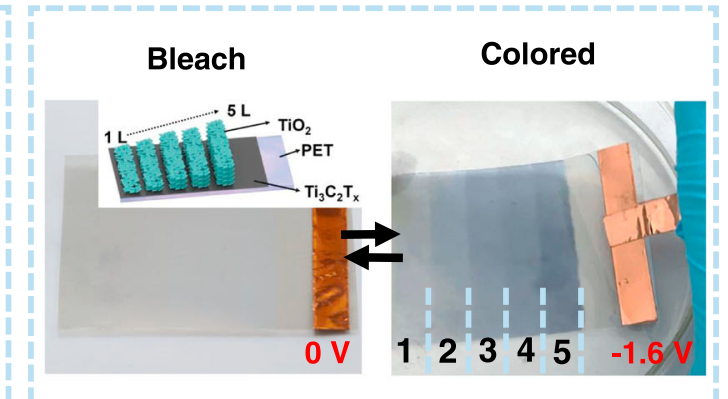

e

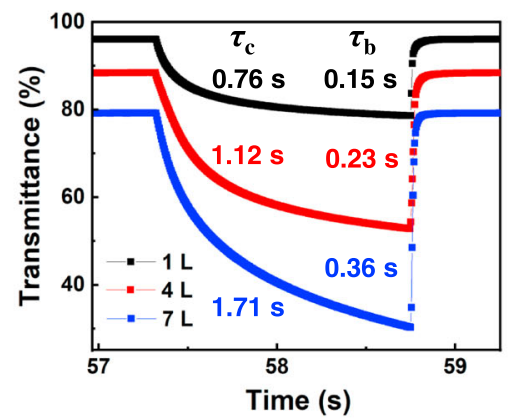

C

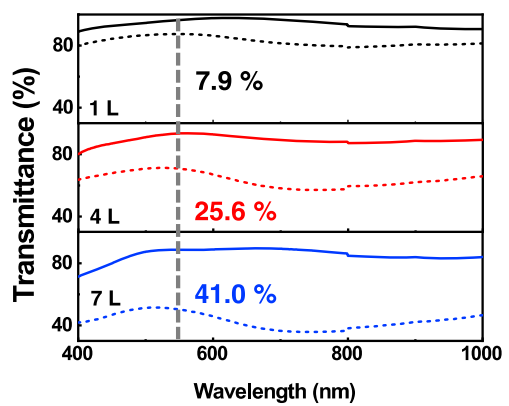

f

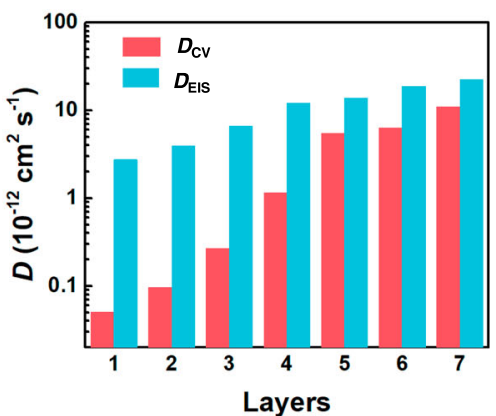

h

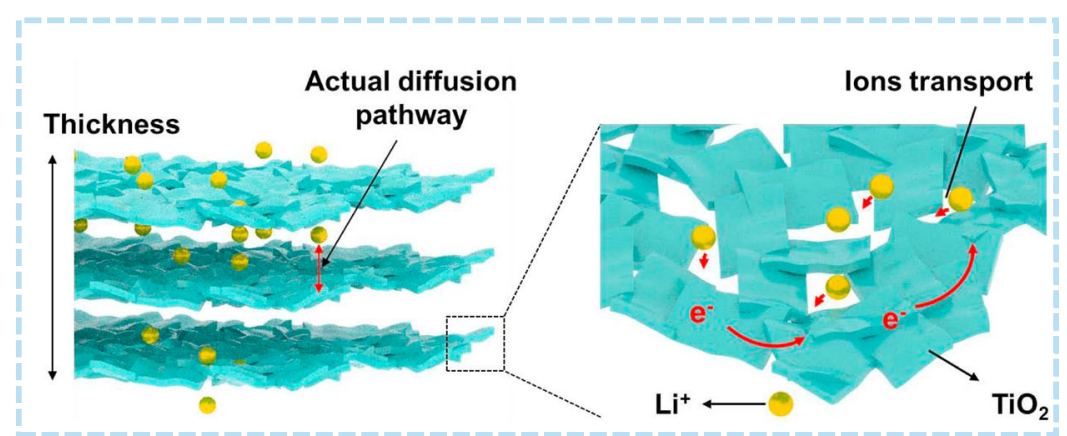

Fig. 4 Electrochromic properties of the $\mathrm{TiO}_{2} / \mathrm{Ti}_{3} \mathbf{C}_{\mathbf{2}} \mathbf{T}_{\mathbf{x}}$ heterostructure. a OM image of a junction between a 1-layer $\mathrm{TiO}_{2}$ film and the $\mathrm{TiO}_{2} / \mathrm{Ti}_{3} \mathrm{C}_{2} \mathrm{~T}_{x}$ heterostructure (Top) (Scale bar: $10 \mu \mathrm{m}$ ), and AFM image and the height profile of across the junction in corresponding area marked in the OM image (Bottom) (Scale bar: $1 \mu \mathrm{m}$ ); b Photographs of the $\mathrm{TiO}_{2} / \mathrm{Ti}_{3} \mathrm{C}_{2} \mathrm{~T}_{x} / \mathrm{PET}$ film with different layers of $\mathrm{TiO}_{2}$ at the bleaching state (no bias) and the colored state (biased at $-1.6 \mathrm{~V}$ ). Inset: structure of $\mathrm{TiO}_{2} / \mathrm{Ti}_{3} \mathrm{C}_{2} \mathrm{~T}_{x} / \mathrm{PET}$ film with different $\mathrm{TiO}_{2}$ layers; $\mathbf{c}$ Optical transmittance spectra with 1, 4, and 7 layers of $\mathrm{TiO}{ }_{2}$ at the biases of $0 \mathrm{~V}$ (solid) and $-1.6 \mathrm{~V}$ (dotted); $\mathbf{d}$ Optical density change $(\Delta \mathrm{OD})$ as a function of the injected charge density for the heterostructures with 1 , 4, and 7 layers of $\mathrm{TiO}_{2}$; e Temporal response of the transmittance at $550 \mathrm{~nm}$ of the heterostructures with 1,4 , and 7 layers of $\mathrm{TiO}_{2}$; $\mathbf{f}$ Diffusion coefficients (D) of the heterostructures with 1-7 layers of $\mathrm{TiO}_{2}$ extracted from the EIS and CV measurements; $\mathbf{g}$ Coloration efficiency (CE) as a function of coloration time $\left(\tau_{\mathrm{c}}\right)$ for the $\mathrm{TiO}_{2} / \mathrm{Ti}_{3} \mathrm{C}_{2} \mathrm{~T}_{\mathbf{x}}$ heterostructures and previously reported $\mathrm{TiO}_{2}$-based structures; $\mathbf{h}$ Schematic of the pathways of electron conduction and ion diffusion within the self-assembled $\mathrm{TiO}_{2}$ thin film.

when no bias is applied, but become translucent with different opacity at the colored state, when emerged in an electrolyte solution ( $1 \mathrm{M} \mathrm{LiClO}_{4} /$ propylene carbonate (PC)) and biased with a constant negative voltage $(-1.6 \mathrm{~V})$. This optical opacity induced by a negative potential is associated with the reduction of $\mathrm{TiO}_{2}$ by $\mathrm{Li}^{+}$counterions and the formation of $\mathrm{Li}_{\mathrm{x}} \mathrm{TiO}_{2}{ }^{45}$.

As the in situ UV-Vis-NIR spectroscopy measurements shown (Fig. $4 \mathrm{c}$ and Supplementary Fig. 12), the optical modulation range $\Delta T$ changes with the increase of the number of layers of the transferred LLIA $\mathrm{TiO}_{2}$ film, where $\Delta T$ is defined as $\Delta T=T_{\mathrm{b}}-T_{\mathrm{c}}=\exp \left(-\alpha_{\mathrm{b}} L\right)$ $-\exp \left(-\alpha_{\mathrm{c}} L\right)\left(T_{\mathrm{b}}\right.$ and $T_{\mathrm{c}}$ are the transmittance of the bleach state and the colored state, $\alpha_{b}$ and $\alpha_{c}$ represent absorption coefficient of the bleach and the colored state of the LLIA film, and L is the thickness of the film). Particularly, $\Delta T$ at the wavelength of $550 \mathrm{~nm}$ increases gradually with the layer numbers of the transferred LLIA $\mathrm{TiO}_{2}$ films $(7.19 \%, 12.26 \%, 21.12 \%, 25.60 \%, 32.12 \%, 38.20 \%$, and $41.09 \%$ from 1 to 7 layers) (Supplementary Table 2). $\Delta T$ reaches its maximum at around $60 \%$ with 15 layers of LLIA $\mathrm{TiO}_{2}$ films and then declines as the layers number reaches to 20 . This is because the transmittance of the bleach state decreases significantly when the film becomes thick, resulting in the decrease of the optical window (Supplementary Fig. 13). We further extracted $\Delta \alpha=\alpha_{\mathrm{c}}$ $\alpha_{\mathrm{b}} \approx\left[\ln \left(T_{\mathrm{c}} / T_{\mathrm{b}}\right)\right] / \mathrm{L}$ from the transmittance spectra. Compared to the $\mathrm{TiO}_{2}$-based EC film prepared using other methods (Supplementary Table 3$)^{16,19,46-59}$, our LLIA $\mathrm{TiO}_{2}$ film shows a $\Delta \alpha$ of $0.12 \mathrm{~nm}^{-1}$, which is about one order of magnitude higher. This 
results suggest that more $\mathrm{TiO}_{2}$ per unit volume in our LLIA $\mathrm{TiO}_{2}$ film participate in the EC process. Such high utilization rate of $\mathrm{TiO}_{2}$ in the LLIA films is one of the key factors responsible for the improved EC performance.

To quantify the utilization rates of both the EC material and the pumped charge, the optical density change $\left(\Delta \mathrm{OD}=\log _{10}\left(T_{\mathrm{b}} / T\right)\right)$ as the function of the pumped charge density $(Q$, calculated by an integration of the driving current density over time) during the coloration half-cycle is measured and plotted in Fig. $4 \mathrm{~d}$. The coloration efficiencies $(\mathrm{CE})^{60}$, defined as the slope of the $\Delta \mathrm{OD}-\mathrm{Q}$ plot when $Q$ is close to 0 , for the LLIA $\mathrm{TiO}_{2}$ films with 1-7 layer numbers are extracted to be 277, 271, 260, 263, 259, 245, and $243 \mathrm{~cm}^{2} \mathrm{C}^{-1}$, respectively (Fig. $4 \mathrm{~d}$ and Supplementary Table 2). These high CE values indicate that small amounts of charge insertion/extraction can result in a large optical modulation (normally CE values of TMO-based EC materials are lower than $100 \mathrm{~cm}^{2} \mathrm{C}^{-1}$ ), which is a results of high utilization rates of both the EC materials and the pumped charges. High CE also guarantees the long-term electrochemical stability. As expected, the LLIA films show maintained optical contrast (up to $95 \%$ of its original value) after 500 EC cycles (Supplementary Fig. 14 and Supplementary Fig. 15). This high cycling stability is essential for practical applications of the EC devices.

The coloration/bleaching time $\tau_{\mathrm{c}} / \tau_{\mathrm{b}}$, another important figureof-merit for EC materials, defined as the time needed for $90 \%$ of the total optical change, is also investigated on the LLIA $\mathrm{TiO}_{2} / \mathrm{Ti}_{3} \mathrm{C}_{2} \mathrm{~T}_{\mathrm{x}}$ heterostructures. The temporal responses of the transmittance at $550 \mathrm{~nm}$ are measured as the bias is switched between -1.6 and $0 \mathrm{~V}$ periodically (Fig. 4e). The coloration/ bleaching times for 1-7 layers of the LLIC $\mathrm{TiO}_{2}$ films are extracted to be $0.76 / 0.15 \mathrm{~s}, 0.73 / 0.12 \mathrm{~s}, 1.03 / 0.20 \mathrm{~s}, 1.03 / 0.23 \mathrm{~s}$, $1.08 / 0.26 \mathrm{~s}, 1.23 / 0.29 \mathrm{~s}$, and $1.71 / 0.36 \mathrm{~s}$ (also summarized in Supplementary Table 2), which are much shorter than those of reported $\mathrm{TiO}_{2}$-based EC devices (generally $>10 \mathrm{~s}$ ) and most reported inorganic materials, and comparable to those of organic EC materials (Supplementary Table 3).

Ion diffusion process inside the EC material plays a crucial role in the EC performance. To further explore the $\mathrm{Li}^{+}$diffusion behavior in the LLIA $\mathrm{TiO}_{2}$ films during the EC process, cyclic voltammetry $(\mathrm{CV})$ and electrochemical impedance spectroscopy (EIS) are measured (details are listed in the Method section). All LLIA films exhibit one pair of redox peaks in their CV curves, corresponding to the reduction and oxidation of $\mathrm{TiO}_{2}$ (Supplementary Fig. 16). According to the EIS results shown in Supplementary Fig. 17 and Supplementary Table 4, the equivalent series resistance (ESR) does not change much as the $\mathrm{TiO}_{2}$ thickness increases from 1 to 7 layers, and the charge-transfer resistance $\left(R_{\mathrm{ct}}\right)$ only raises from 8.7 to $15.7 \Omega$, indicating that multilayer stacking does not decrease the conductivity and charge-transfer speed much at the interface of the $\mathrm{TiO}_{2}$ film and electrolyte.

The apparent ion diffusion coefficient $D$, which represents the kinetics of ion insertion/extraction in the EC film, can be extracted either from the scanning-rate-dependent CV measurements, or from the Warburg region of the Bode plot obtained from the EIS measurements (see methods for details about the extraction methods of $D)^{61}$. As shown in Fig. 4 f, the $D$ values extracted from the $\mathrm{CV}$ and from the EIS measurements are $5.05 \times 10^{-14}, 9.63 \times 10^{-14}, 2.68 \times 10^{-13}, 1.15 \times 10^{-12}$, $5.45 \times 10^{-12}, 6.29 \times 10^{-12}$, and $1.10 \times 10^{-11} \mathrm{~cm}^{2} \mathrm{~s}^{-1}$, and $2.75 \times 10^{-12}, 3.94 \times 10^{-12}, 6.59 \times 10^{-12}, 1.21 \times 10^{-11}, 1.39 \times$ $10^{-11}, 1.88 \times 10^{-11}, 2.24 \times 10^{-11} \mathrm{~cm}^{2} \mathrm{~s}^{-1}$, respectively, as the number of layer of the $\mathrm{TiO}_{2}$ film increases from 1 to 7 . The positive correlation between $D$ and the layer number is attributed to the increased effective electrochemical area of the LLIA $\mathrm{TiO}_{2}$ film due to its high surface-to-volume ratio, which will be explained later.

To benchmark the overall EC performance, the values of $C E$ and $\tau_{\mathrm{c}}$ of the LLIA $\mathrm{TiO}_{2} / \mathrm{Ti}_{3} \mathrm{C}_{2} \mathrm{~T}_{\mathrm{x}}$ heterostructures as well as previously reported EC materials are summarized in Fig. $4 \mathrm{~g}$ and Supplementary Table 3 . It is clearly observed that both the $C E$ and the response time of our proposed structures are several times or even one order of magnitude better than those from both other materials such as $\mathrm{WO}_{3}$, and other nanostructured $\mathrm{TiO}_{2}$, including dense films and other $0 \mathrm{D}$ or $1 \mathrm{D}$ nanostructures, and comparable to organic materials. Moreover, the good cycling stability of our LLIA $\mathrm{TiO}_{2} / \mathrm{Ti}_{3} \mathrm{C}_{2} \mathrm{~T}_{\mathrm{x}}$ heterostructures could address the ultraviolet/electrochemical decomposition issues in traditional organic materials in practical applications ${ }^{18}$.

We believe that the superiority of the EC performance of the LLIA $\mathrm{TiO}_{2} / \mathrm{Ti}_{3} \mathrm{C}_{2} \mathrm{~T}_{\mathrm{x}}$ heterostructures mainly results from the $2 \mathrm{D}$ nature of the $\mathrm{TiO}_{2}$ flakes as well as the loosely networked structures. To understand this, we propose two possible ion transport pathways ${ }^{15}$. The first ion transport pathway is that the $\mathrm{Li}^{+}$ions enters the EC material only on the top surface, and the redoxation deeper into the EC material is accessed by inter-crystal-lattice diffusion of $\mathrm{Li}^{+}$ions; whereas in the second ion transport pathway (as illustrated in Fig. 4h), $\mathrm{Li}^{+}$ions could travel to all the surfaces of individual EC nanostructures efficiently in the liquid phase, and as a result, the diffusion and the redoxation take place throughout the entire EC nanostructures simultaneously. For dense films, only the first pathway takes place, resulting in very bad coloration efficiency and very slow coloration/bleaching time; while for nanostructured films (including our 2D nanostructures and previously reported $0 \mathrm{D}$ or $1 \mathrm{D}$ nanostructures), the second pathway, which is much more efficient and much faster, starts to play an important role. The higher probability the second pathway takes place in a nanostructured film, the better EC performance it can achieve.

Our experimental results suggest that the second pathway is the dominating $\mathrm{Li}^{+}$ion transport mechanism in our selfassembled $2 \mathrm{D} \mathrm{TiO}_{2}$ films. First, the high $C E$ and its small decrease with the thickness suggest that $\mathrm{Li}^{+}$ions can easily access all the $\mathrm{TiO}_{2}$ flakes regardless of the depth of them from the top surface of the film. Second, the color change time $\tau\left(\tau_{\mathrm{c}}\right.$ or $\left.\tau_{\mathrm{b}}\right)$ is fast and stays almost the same with different thicknesses. Given that $\tau$ is proportional to the square of the depth of the diffusion, we speculate that the effective diffusion depth is likely to be determined by the average thickness of individual $\mathrm{TiO}_{2}$ flakes, rather than the thickness of the entire assembled $\mathrm{TiO}_{2}$ film. Last, the increasing trend between $D$ and the thickness indicates that it is less likely that the extremely slow internanosheet diffusion is contributed to the measured apparent diffusion coefficient. Instead, $D$ follows a parabolic trend with the thickness (see Supplementary Fig. 18), or the number of layers, which agrees well if considering the contribution from the electrochemical area $A_{\mathrm{EC}}$ and assuming a linear increase of $A_{\mathrm{EC}}$ with the number of layers, that is, $D \sim\left(A_{\mathrm{EC}} / A\right)^{2} D_{0} \propto N^{2}$, where $A$ is the geometrical area, $D_{0}$ is the intrinsic diffusion coefficient, and $N$ is the number of layers. All these experimental observations can be explained well if the performance is governed by the second ion transport pathway, in which all the surfaces of the $2 \mathrm{D} \mathrm{TiO}_{2}$ flakes are interfacing well with the electrolyte, and the actual diffusion length is approximately the thickness of individual $\mathrm{TiO}_{2}$ flakes (Fig. 4h). As a comparison, for $1 \mathrm{D}$ or $0 \mathrm{D}$ nanostructures, although the ideal surface-to-volume might be even larger, the surfaces may not be fully exposed to the electrolyte because of the denser packing of these nanostructures in a film. Consequently, the $\mathrm{Li}^{+}$ions have to undergo the first pathway in order to access the deeper EC materials, which tremendously limits the speed and thus reduces the coloration efficiency. 
a

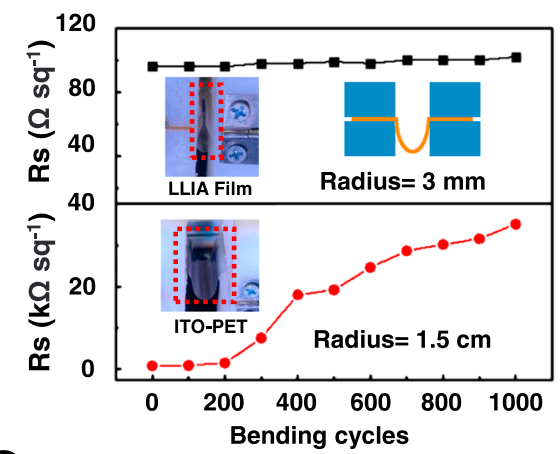

b

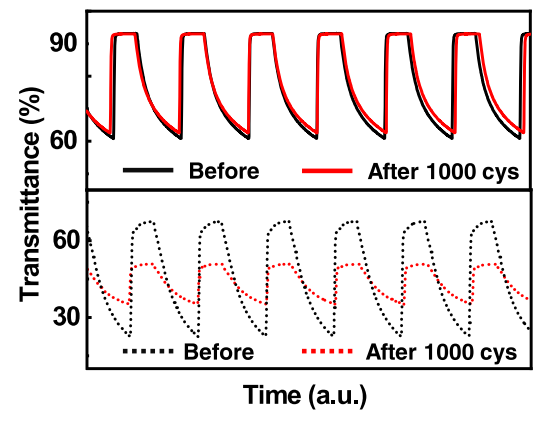

C

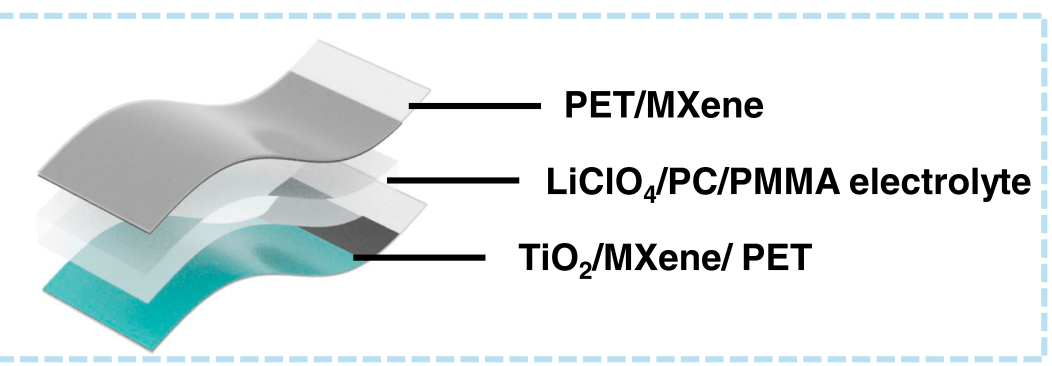

d

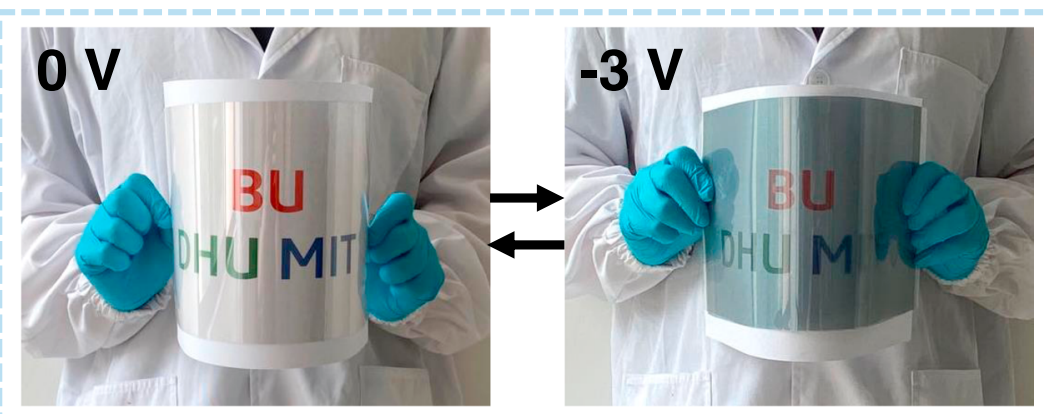

e

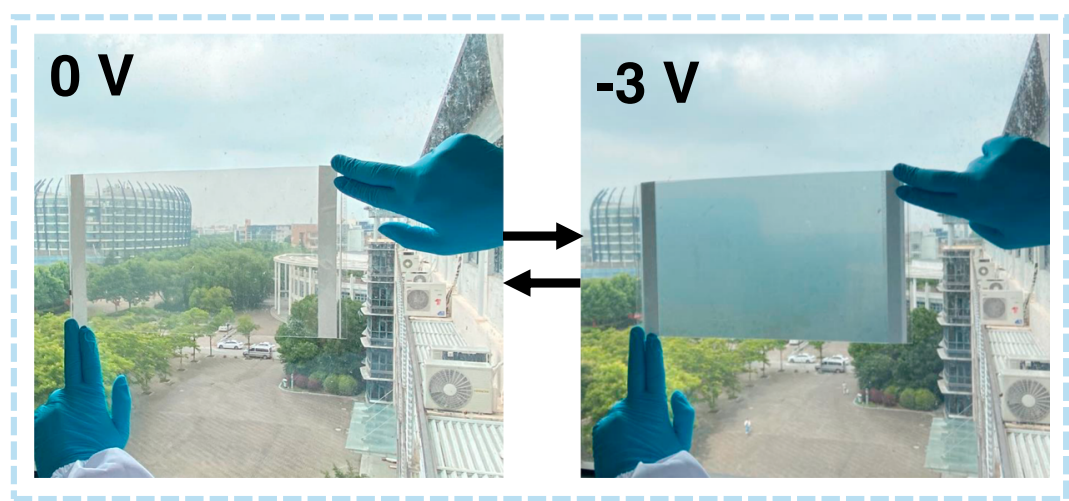

Fig. 5 Mechanical properties of the $\mathrm{TiO}_{2} / \mathrm{Ti}_{3} \mathrm{C}_{2} \mathrm{Tx}$ heterostructure and demonstration of a large-area flexible EC device. a Comparison of the sheet resistance $\left(R_{\mathrm{S}}\right)$ of the LLIA Ti ${ }_{3} \mathrm{C}_{2} \mathrm{~T}_{x} / \mathrm{PET}$ and the ITO/PET films after 1000 bending cycles; $\mathbf{b}$ Comparison of the electrochromic switching behaviors of the $\mathrm{LLIA} \mathrm{TiO} 2 / \mathrm{Ti}_{3} \mathrm{C}_{2} \mathrm{~T}_{x} / \mathrm{PET}$ and the ITO/PET films after 1000 bending cycles; $\mathbf{c}$ Schematic diagram of the flexible solid electrochromic device; $\mathbf{d}$, e As-prepared solid electrochromic device with an A4 paper size (about $20 \times 30 \mathrm{~cm}$ ) is $\mathbf{d}$ triggered in bending state and $\mathbf{e}$ attached on a window.

$\mathrm{MXene} / \mathrm{TiO}_{2}$ heterostructure enabled flexible EC devices for large-area applications. The overall flexibility of an EC device is determined by the most rigid layer. In our $\mathrm{TiO}_{2} / \mathrm{Ti}_{3} \mathrm{C}_{2} \mathrm{~T}_{\mathrm{x}}$ heterostructure, both the EC layer and the transparent electrode have superior mechanical bendability. To confirm this, bending test is performed on the as-fabricated LLIA electrode. As shown in Fig. 5a, the resistance of the $\mathrm{Ti}_{3} \mathrm{C}_{2} \mathrm{~T}_{\mathrm{x}} / \mathrm{PET}$ film increases by only $6 \%$ after 1000 bending and release cycles at a bending radius of $0.3 \mathrm{~cm}$, whereas the sheet resistance of a commercial ITO/PET film increases quickly by three orders of magnitude after 1000 bending cycles even at a much larger bending radius of $1.5 \mathrm{~cm}$. The EC optical switching behaviors of the $\mathrm{TiO}_{2} / \mathrm{Ti}_{3} \mathrm{C}_{2} \mathrm{~T}_{\mathrm{x}} / \mathrm{PET}$ film and the $\mathrm{TiO}_{2} / \mathrm{ITO} / \mathrm{PET}$ before and after 1000 bending cycles are also tested (Fig. $5 b$ ). $\Delta T$ of the $\mathrm{TiO}_{2} / \mathrm{Ti}_{3} \mathrm{C}_{2} \mathrm{~T}_{\mathrm{x}} / \mathrm{PET}$ electrode remains at $94 \%$ of its original value after 1000 bending cycles. In contrast, $\Delta T$ of the $\mathrm{TiO}_{2} / \mathrm{ITO} / \mathrm{PET}$ electrode drops to about $30 \%$ after 1000 cycles. 
Finally, a large-area flexible EC device with a dimension of $30 \times$ $20 \mathrm{~cm}$ are demonstrated as an example for practical large-area applications. As shown in Fig. $5 c$, it is composed of a LLIA $\mathrm{TiO}_{2} /$ $\mathrm{Ti}_{3} \mathrm{C}_{2} \mathrm{~T}_{\mathrm{x}}$ heterostructure on a PET substrate as the EC electrode, another LLIA $\mathrm{Ti}_{3} \mathrm{C}_{2} \mathrm{~T}_{\mathrm{x}} / \mathrm{PET}$ film as the counter electrode, and a $1 \mathrm{M} \mathrm{LiClO}_{4} / \mathrm{PC} /$ Poly(methyl methacrylate) (PMMA) layer as the electrolyte. Benefiting from the exceptional optical memory effect of $\mathrm{TiO}_{2}$ based materials, the EC device can maintain its coloration state after disconnecting from the voltage supply (Fig. 5d, e), which is advantageous for energy saving in future applications. The EC device presents a uniform color distribution even in the bending state, which opens up the possibility of scaling up this technology for applications, such as flexible displays, smart windows, and other ubiquitous electronics. In addition, the flexible solid EC device also exhibits excellent cycling stability, demonstrated by the 92\% transmittance presentation after 1000 EC cycles between the bias of $-3 \mathrm{~V}$ and $1 \mathrm{~V}(\mathbf{S})$.

\section{Discussion}

In summary, high performance and flexible EC devices are realized based on assembled $2 \mathrm{D} \mathrm{TiO}_{2} / \mathrm{Ti}_{3} \mathrm{C}_{2} \mathrm{~T}_{\mathrm{x}}$ heterostructures. This success benefits from several important achievements in this work, including the realization of single crystalline $2 \mathrm{D} \mathrm{TiO}_{2}$ flakes with micrometer large lateral sizes and nanometer thin thicknesses, and the liquid/liquid interfacial self-assembly technique enabled mass production of MXene and 2D TMO films with excellent uniformity. We expect our approach to synthesize 2D $\mathrm{TiO}_{2}$ crystals to be developed to a general methodology for the synthesis of high-quality 2D MXene derivatives. Also, the selfassembled MXene films could be used as flexible, transparent, and porous electrodes in large-scale electronic, optoelectronic, and energy-harvesting applications. Our performance test clearly shows that exceptional electrochromic efficiency, fast coloration speed, and excellent mechanical flexibility are achieved simultaneously on the self-assembled 2D TMO/MXene heterostructuresbased EC devices, thanks to the unique electrical, electrochemical, and mechanical properties of the networked 2D nanostructures. Finally, a large-area flexible EC device is demonstrated, paving the way for integrating EC devices to next-generation flexible and wearable electronics.

\section{Methods \\ Chemicals. All the starting materials are available commercially and used as received. Polyethylene terephthalate (PET) was rinsed sequentially in the baths of deionized water, acetone, and isopropanol. $\mathrm{Ti}_{3} \mathrm{AlC}_{2}$ (MAX-Phase, purchased from 11 Technology Co. Ltd), lithium fluoride (LiF, Alfa Aesar, 99.99\%), hydrochloric acid ( $\mathrm{HCl}$, Fisher Chemical, 6M), 1-hexene (Acros Organics, 99\%), isopropyl alcohol (IPA, Fisher Chemical, 99\%), propylene carbonate (PC, Alfa Aesar, 99\%), lithium perchlorate $\left(\mathrm{LiClO}_{4}\right.$, Acros Organics, 99+\%), and poly(methyl methacry- late) (PMMA, ACROS Organics, M.W. 35000) were utilized without initial treatments.}

\section{Synthesis and interfacial assembly of $\mathrm{Ti}_{3} \mathrm{C}_{\mathbf{2}} \mathbf{T}_{\mathbf{x}}$ and 2D $\mathrm{TiO}_{2}$ films. $\mathrm{Ti}_{3} \mathrm{AlC}_{2}$} etching was performed following Gogosti et al.'s work ${ }^{22}$ to prepare $2 \mathrm{D} \mathrm{Ti}_{3} \mathrm{C}_{2} \mathrm{~T}_{\mathrm{x}}$. Briefly, $1.6 \mathrm{~g}$ lithium fluoride was dissolved into $5 \mathrm{~mL}$ of DI water with $15 \mathrm{~mL} 12 \mathrm{M}$ hydrochloric acid solution in a plastic bottle as the etchant solution. Then $1 \mathrm{~g} \mathrm{Ti}_{3} \mathrm{AlC}_{2}$ (MAX phase) powders was gradually added to the etchant solution within $5 \mathrm{~min}$ and the reaction is maintained with stirring the reactants at $40{ }^{\circ} \mathrm{C}$ in a silicon oil bath for $24 \mathrm{~h}$. Etched MXene was washed with DI water, and separated through centrifugation at $1988 \times g$ for $5 \mathrm{~min}$. Washing was repeated several times until a stable dark supernatant solution of $\mathrm{Ti}_{3} \mathrm{C}_{2} \mathrm{~T}_{\mathrm{x}}$ flakes with a $\mathrm{pH}$ value of around 6 was obtained. The solution was subsequently centrifuged for $30 \mathrm{~min}$ at $3500 \mathrm{rpm}$, after which a dark sediment of $\mathrm{Ti}_{3} \mathrm{C}_{2} \mathrm{~T}_{\mathrm{x}}$ was observed and then collected.

The $\mathrm{Ti}_{3} \mathrm{C}_{2} \mathrm{~T}_{\mathrm{x}}$ sedimen was diluted to $0.2 \mathrm{mg} / \mathrm{ml}$ with DI water, and then, the solution were freeze dried at $-47^{\circ} \mathrm{C}$ for days to form an aerogel. To obtaine the $\mathrm{TiO}_{2}$ aerogel, the $\mathrm{Ti}_{3} \mathrm{C}_{2} \mathrm{~T}_{\mathrm{x}}$ aerogel was put in a ceramic boat and annealed at the temperature of $400{ }^{\circ} \mathrm{C}$ for $50 \mathrm{~h}$ with the heating rate of $1{ }^{\circ} \mathrm{C} / \mathrm{min}$.
To assemble the $\mathrm{Ti}_{3} \mathrm{C}_{2} \mathrm{~T}_{\mathrm{x}}$ flakes into a continuous film, the $\mathrm{Ti}_{3} \mathrm{C}_{2} \mathrm{~T}_{\mathrm{x}}$ aerogel was dispersed in an IPA solution $(2 \mathrm{mg} / \mathrm{ml})$ by sonicating for $30 \mathrm{~min}$. Hexane was carefully poured on the top of DI water to setup an interface between these two liquids. Then, the $\mathrm{Ti}_{3} \mathrm{C}_{2} \mathrm{~T}_{\mathrm{x}} / \mathrm{IPA}$ dispersion was slowly injected near the interface to form a continuous film. After removing the top hexane layer, the self-assembly film was transferred onto a substrate and annealed at $90{ }^{\circ} \mathrm{C}$ in vacuum for $50 \mathrm{~h}$ $(<0.05 \mathrm{MPa})$.

The assembly of the $\mathrm{TiO}_{2}$ films is similar to the $\mathrm{Ti}_{3} \mathrm{C}_{2} \mathrm{~T}_{\mathrm{x}}$ assembly process. For multilayered $\mathrm{TiO}_{2}$ film, the transferred films were dried at $60^{\circ} \mathrm{C}$ in vacuum for $1 \mathrm{~h}$, and then treated with oxygen plasma (the oxygen gas flow rate is $50 \mathrm{sccm}$, and the plasma power is $100 \mathrm{~W}$ ) for $30 \mathrm{~s}$ before each transfer cycle. The $\mathrm{TiO}_{2} / \mathrm{Ti}_{3} \mathrm{C}_{2} \mathrm{~T}_{\mathrm{x}}$ heterostructures were annealed at $90^{\circ} \mathrm{C}$ in vacuum $(<0.05 \mathrm{MPa})$ for $50 \mathrm{~h}$ before use.

Assembly of the Electrochromic device. The electrolyte gel was obtained by mixing $1 \mathrm{M} \mathrm{LiClO}_{4}$ in a PC solution and $20 \mathrm{wt} \%$ PMMA (relative to the $\mathrm{LiClO}_{4} / \mathrm{PC}$ solution). For the large-area $(20 \times 30 \mathrm{~cm})$ electrode, silver paste line is screen printed around the $\mathrm{Ti}_{3} \mathrm{C}_{2} \mathrm{~T}_{\mathrm{x}} / \mathrm{PET}$ film and then protected by continuous printed $\mathrm{UV}$ curing resin to improve the electrical conductivity. The EC devices were fabricated by hot pressing the electrolyte gel sandwiched betwen the $\mathrm{TiO}_{2} / \mathrm{Ti}_{3} \mathrm{C}_{2} \mathrm{~T}_{\mathrm{x}} /$ PET electrode and the $\mathrm{Ti}_{3} \mathrm{C}_{2} \mathrm{~T}_{\mathrm{x}} / \mathrm{PET}$ counter electrode with a scotch tape spacer (with the thickness of $1 \mathrm{~mm}$ ) at $60^{\circ} \mathrm{C}$.

Material characterization. X-ray diffraction (XRD) patterns were measured using an X-ray diffractometer (Bruker AXS X8 Proteum-R instrument) with the radiation at $40 \mathrm{kV}$ and $200 \mathrm{~mA}$. Raman spectroscopy measurements were performed on a Renishaw inVia Raman microscope equipped with a $532 \mathrm{~nm}$ laser line (The laser power on the samples is about $1.6 \mathrm{~mW}$ ). All the spectra in comparison were taken under the same conditions. Transmission electron microscopy (TEM) measurements were performed on a FEI Tecnai Osiris TEM. Selected area electron diffraction (SAED) was measured on a JEOL 2100 TEM. AFM measurements were conducted on a Bruker Dimension system. X-ray photoelectron spectroscopy (XPS) measurements were performed using a PHI Versaprobe II. The UV-vis spectroscopy was carried out using a Agilent CARY 5000.

Electrochemical measurements and parameter extraction. Electrochemical measurements were carried out in a PC solution containing $1 \mathrm{M} \mathrm{LiClO}_{4}$ electrolyte using three-electrode electrochemical cells with the $\mathrm{TiO}_{2} / \mathrm{Ti}_{3} \mathrm{C}_{2} \mathrm{~T}_{\mathrm{x}} / \mathrm{PET}$ films as the working electrodes, a platinum plate as the counter electrode, and a freshly prepared $\mathrm{Ag} / \mathrm{Ag}^{+}$as the pseudo-reference electrode (calibrated by ferrocene). Electrochemical impedance spectroscopy (EIS) and cycle voltammetry (CV) were conducted by an electrochemical workstation (Bio-logic SAS, VSP-300) over a frequency range of $100 \mathrm{mHz}-1000 \mathrm{KHz}$.

The measured EIS spectra was fitted with a circuit model illustrated in $u$. The Nyquist plot of all films is composed of three parts: an equivalent series resistance (ESR) in series with a semicircle consisting of a non-faradaic double layer capacitance $\left(C_{\mathrm{dl}}\right)$ and a charge-transfer resistance $\left(R_{\mathrm{ct}}\right)$ at high frequency; a $45^{\circ}$ linear region representing the Warburg element $(W)$, which captures the ion diffusion process at medium frequency; and a line related to the capacitive charging behavior of the pseudo-capacitance $\left(C_{\mathrm{p}}\right)$ of $\mathrm{TiO}_{2}$ film and its bulk resistance $\left(R_{\mathrm{p}}\right)$ at low frequency.

The apparent ion diffusion coefficient $D$ can be extracted from both the EIS measurements and the CV measurements. In the first method, $D_{\text {EIs }}$ can be calculated from the Warburg region according to Eqs. (1) and (2):61,62

$$
\begin{gathered}
Z_{w}=\sigma \omega^{-1 / 2} \\
D_{\mathrm{EIS}}=R^{2} T^{2} /\left(2 A^{2} n^{4} F^{4} C^{2} \sigma^{2}\right)
\end{gathered}
$$

where $\sigma$ is the slope of $Z_{\mathrm{w}}$ against $\omega^{-1 / 2}, R$ is the gas constant, $T$ is the absolute temperature, $A$ is the effective working area (geometrical area), $n$ is the number of electrons involved in the electrochemical reaction, $F$ and $C$ are the Faraday constant and the molar concentration of $\mathrm{Li}^{+}$ions.

In the second method, the apparent ion diffusion coefficients $D_{\mathrm{CV}}$ can be calculated by: ${ }^{63}$

$$
i_{p}=2.687 \times 10^{5} \times n^{3 / 2} \times D_{C V}^{1 / 2} \times C \times A \times v^{1 / 2}
$$

where $v$ represents the potential sweeping rate, $i_{\mathrm{p}}$ represents the peak current density.

\section{Data availability}

All data needed to evaluate the conclusions in the paper are present in the paper and/or the Supplementary Information. Additional data related to this paper may be requested from the authors.

Received: 19 July 2020; Accepted: 4 February 2021; Published online: 11 March 2021 


\section{References}

1. Rosseinsky, D. R. \& Mortimer, R. J. Electrochromic systems and the prospects for devices. Adv. Mater. 13, 783-793 (2001).

2. Somani, P. R. \& Radhakrishnan, S. Electrochromic materials and devices: present and future. Mater. Chem. Phys. 77, 117-133 (2003).

3. Cong, S., Tian, Y., Li, Q., Zhao, Z. \& Geng, F. Single-crystalline tungsten oxide quantum dots for fast pseudocapacitor and electrochromic applications. Adv. Mater. 26, 4260-4267 (2014)

4. Mortimer, R. J., Dyer, A. L. \& Reynolds, J. R. Electrochromic organic and polymeric materials for display applications. Displays 27, 2-18 (2006).

5. Zhang, S., Cao, S., Zhang, T., Fisher, A. \& Lee, J. Y. $\mathrm{Al}^{3+}$ intercalation/deintercalation-enabled dual-band electrochromic smart windows with a high optical modulation, quick response and long cycle life. Energy Environ. Sci. 11, 2884-2892 (2018).

6. Yan, C. et al. Stretchable and wearable electrochromic devices. ACS Nano 8, 316-322 (2014).

7. Wen, R. T., Granqvist, C. G. \& Niklasson, G. A. Eliminating degradation and uncovering ion-trapping dynamics in electrochromic $\mathrm{WO}_{3}$ thin films. Nat. Mater. 14, 996-1001 (2015).

8. Fu, Z. et al. Rational design of flexible two-dimensional MXenes with multiple functionalities. Chem. Rev. 119, 11980-12031 (2019).

9. Chen, J. et al. Recent progress and advances in the environmental applications of MXene related materials. Nanoscale 12, 3574-3592 (2020).

10. Shahzad, A. et al. Heterostructural $\mathrm{TiO}_{2} / \mathrm{Ti}_{3} \mathrm{C}_{2} \mathrm{~T}_{\mathrm{x}}$ (MXene) for photocatalytic degradation of antiepileptic drug carbamazepine. Chem. Eng. J. 349, 748-755 (2018).

11. Dong, Y. et al. $\mathrm{Ti}_{3} \mathrm{C}_{2}$ MXene-derived sodium/potassium titanate nanoribbons for high-performance sodium/potassium ion batteries with enhanced capacities. ACS Nano 11, 4792-4800 (2017).

12. Pang, J. et al. Applications of $2 \mathrm{D}$ MXenes in energy conversion and storage systems. Chem. Soc. Rev. 48, 72-133 (2019).

13. Cai, G., Ciou, J. H., Liu, Y., Jiang, Y. \& Lee, P. S. Leaf-inspired multiresponsive MXene-based actuator for programmable smart devices. Sci. Adv. 5, eaaw7956 (2019).

14. Salles, P. et al. Electrochromic effect in titanium carbide MXene thin films produced by dip-coating. Adv. Funct. Mater. 29, 1809223 (2019).

15. Wang, C., Shim, M. \& Guyot-Sionnest, P. Electrochromic nanocrystal quantum dots. Science 291, 2390-2392 (2001).

16. Chen, J. Z., Ko, W. Y., Yen, Y. C., Chen, P. H. \& Lin, K. J. Hydrothermally processed $\mathrm{TiO}_{2}$ nanowire electrodes with antireflective and electrochromic properties. ACS Nano 6, 6633-6639 (2012).

17. Nah, Y. C., Ghicov, A., Kim, D., Berger, S. \& Schmuki, P. $\mathrm{TiO}_{2}-\mathrm{WO}_{3}$ composite nanotubes by alloy anodization: growth and enhanced electrochromic properties. J. Am. Chem. Soc. 130, 16154-16155 (2008).

18. Jensen, J., Madsen, M. V. \& Krebs, F. C. Photochemical stability of electrochromic polymers and devices. J. Mater. Chem. C. 1, 4826-4835 (2013).

19. Azam, A. et al. Two-dimensional $\mathrm{WO}_{3}$ nanosheets chemically converted from layered $\mathrm{WS}_{2}$ for high-performance electrochromic devices. Nano Lett. 18 , 5646-5651 (2018).

20. Li, K., Zhang, Q., Wang, H. \& Li, Y. Lightweight, highly bendable and foldable electrochromic films based on all-solution-processed bilayer nanowire networks. J. Mater. Chem. C. 4, 5849-5857 (2016).

21. Liang, L. et al. High-performance flexible electrochromic device based on facile semiconductor-to-metal transition realized by $\mathrm{WO}_{3} \cdot{ }_{2} \mathrm{H}_{2} \mathrm{O}$ ultrathin nanosheets. Sci. Rep. 3, 1936 (2013).

22. Alhabeb, M. et al. Guidelines for synthesis and processing of two-dimensional titanium carbide $\left(\mathrm{Ti}_{3} \mathrm{C}_{2} \mathrm{~T}_{\mathrm{x}}\right.$ MXene). Chem. Mater. 29, 7633-7644 (2017).

23. Khalifa, Z. S., Lin, H. \& Ismat, S. Shah, structural and electrochromic properties of $\mathrm{TiO}_{2}$ thin films prepared by metallorganic chemical vapor deposition. Thin Solid Films 518, 5457-5462 (2010).

24. van de Krol, R., Goossens, A. \& Meulenkamp, E. A. In situ X-ray diffraction of lithium intercalation in nanostructured and thin film anatase $\mathrm{TiO}_{2}$. $J$. Electrochem. Soc. 146, 3150 (1999).

25. Khatim, O. et al. Amorphous-anatase phase transition in single immobilized $\mathrm{TiO}_{2}$ nanoparticles. Chem. Phys. Lett. 558, 53-56 (2013).

26. Gao, X. T. et al. Ultrathin MXene nanosheets decorated with $\mathrm{TiO}_{2}$ quantum dots as an efficient sulfur host toward fast and stable Li-S batteries. Small 14, 1802443 (2018).

27. Cao, J. et al. Realization of $2 \mathrm{D}$ crystalline metal nitrides via selective atomic substitution. Sci. Adv. 6, eaax8784 (2020).

28. Yu, X., Prévot, M. S., Guijarro, N. \& Sivula, K. Self-assembled $2 \mathrm{D} \mathrm{WSe}_{2}$ thin films for photoelectrochemical hydrogen production. Nat. Commun. 6, 7596 (2015).

29. Sternling, C. V. \& Scriven, L. E. Interfacial turbulence: hydrodynamic instability and the marangoni effect. AIChE J. 5, 514-523 (1959).

30. Zhang, C. et al. Transparent, flexible, and conductive 2D titanium carbide (MXene) films with high volumetric capacitance. Adv. Mater. 29, 1702678 (2017).
31. Hantanasirisakul, K. et al. Fabrication of $\mathrm{Ti}_{3} \mathrm{C}_{2} \mathrm{~T}_{\mathrm{x}} \mathrm{MXene}$ transparent thin films with tunable optoelectronic properties. Adv. Electron. Mater. 2, 1600050 (2016).

32. Li, X. et al. Large-area ultrathin graphene films by single-step marangoni selfassembly for highly sensitive strain sensing application. Adv. Funct. Mater. 26 1322-1329 (2016)

33. Min, K. et al. A facile route to fabricate stable reduced graphene oxide dispersions in various media and their transparent conductive thin films. $J$. Colloid Interface Sci. 383, 36-42 (2012).

34. Ying, G., Dillon, A. D., Fafarman, A. T. \& Barsoum, M. W. Transparent, conductive solution processed spincast $2 \mathrm{D} \mathrm{Ti}_{2} \mathrm{CT}_{\mathrm{x}}$ (MXene) films. Mater. Res. Lett. 5, 391-398 (2017).

35. Mariano, M. et al. Solution-processed titanium carbide MXene films examined as highly transparent conductors. Nanoscale 8, 16371-16378 (2016).

36. Weng, G.-M. et al. Layer-by-layer assembly of cross-functional semitransparent MXene-carbon nanotubes composite films for next-generation electromagnetic interference shielding. Adv. Funct. Mater. 28, 1803360 (2018).

37. Kim, S. J. et al. Interfacial assembly of ultrathin, functional MXene films. ACS Appl. Mater. Inter. 11, 32320-32327 (2019).

38. Zhang, C. \& Nicolosi, V. Graphene and MXene-based transparent conductive electrodes and supercapacitors. Energy Storage Mater. 16, 102-125 (2019).

39. Ying, G., Kota, S., Dillon, A. D., Fafarman, A. T. \& Barsoum, M. W. Conductive transparent $\mathrm{V}_{2} \mathrm{CT}_{\mathrm{x}}$ (MXene) films. FlatChem 8, 25-30 (2018).

40. Salles, P., Quain, E., Kurra, N., Sarycheva, A. \& Gogotsi, Y. Automated scalpel patterning of solution processed thin films for fabrication of transparent MXene microsupercapacitors. Small 14, 1802864 (2018).

41. Schultz, T., Frey, N. C., Hantanasirisakul, K., Park, S., May, S. J., Shenoy, V. B., Gogotsi, Y. \& Koch, N. Surface termination dependent work function and electronic properties of $\mathrm{Ti}_{3} \mathrm{C}_{2} \mathrm{~T}_{\mathrm{x}}$ MXene. Chem. Mater. 31, 6590-6597 (2019).

42. Wang, $\mathrm{H}$. et al. Formation of Quasi-core-shell $\mathrm{In}_{2} \mathrm{~S}_{3}$ /anatase $\mathrm{TiO}_{2} @$ metallic $\mathrm{Ti}_{3} \mathrm{C}_{2} \mathrm{~T}_{\mathrm{x}}$ hybrids with favorable charge transfer channels for excellent visiblelight-photocatalytic performance. Appl. Catal. B Environ. 233, 213-225 (2018).

43. Park, Y., Choong, V., Gao, Y., Hsieh, B. R. \& Tang, C. W. Work function of indium tin oxide transparent conductor measured by photoelectron spectroscopy. Appl. Phys. Lett. 68, 2699-2701 (1996).

44. Peng, C. et al. High efficiency photocatalytic hydrogen production over ternary $\mathrm{Cu} / \mathrm{TiO}_{2} @ \mathrm{Ti}_{3} \mathrm{C}_{2} \mathrm{~T}_{\mathrm{x}}$ enabled by low-work-function 2D titanium carbide. Nano Energy 53, 97-107 (2018).

45. Ghicov, A. et al. $\mathrm{TiO}_{2}$ nanotubes: $\mathrm{H}^{+}$insertion and strong electrochromic effects. Electrochem. Commun. 8, 528-532 (2006).

46. Dinh, N. N., Oanh, N. T. H. T., Long, P. D., Bernard, M. C. \& Goff, A. H. Electrochromic properties of $\mathrm{TiO}_{2}$ anatase thin films prepared by a dipping sol-gel method. Thin Solid Films 423, 70-76 (2003).

47. Tebby, Z. et al. Low-temperature UV-processing of nanocrystalline nanoporous thin $\mathrm{TiO}_{2}$ films: an original route toward plastic electrochromic systems. Chem. Mater. 20, 7260-7267 (2008).

48. Chen, Y. et al. Design and construction of hierarchical $\mathrm{TiO}_{2}$ nanorod arrays by combining layer-by-layer and hydrothermal crystallization techniques for electrochromic application. Appl. Surf. Sci. 440, 217-223 (2018).

49. Patil, R. A., Devan, R. S., Liou, Y. \& Ma, Y. R. Efficient electrochromic smart windows of one-dimensional pure brookite $\mathrm{TiO}_{2}$ nanoneedles. Sol. Energy Mater. Sol. Cells 147, 240-245 (2016).

50. Chen, Y. et al. Core-shell nanorod arrays of crystalline/amorphous $\mathrm{TiO}_{2}$ constructed by layer-by-layer method for high-performance electrochromic electrodes. Electrochim. Acta 251, 546-553 (2017).

51. Alesanco, Y. et al. Plastic electrochromic devices based on viologen-modified $\mathrm{TiO}_{2}$ films prepared at low temperature. Sol. Energy Mater. Sol. Cells 157, 624-635 (2016).

52. $\mathrm{Li}, \mathrm{R}$. et al. Ion-transport design for high-performance $\mathrm{Na}^{+}$-based electrochromics. ACS Nano 12, 3759-3768 (2018).

53. Wang, J. L., Lu, Y. R., Li, H. H., Liu, J. W. \& Yu, S. H. Large area co-assembly of nanowires for flexible transparent smart windows. J. Am. Chem. Soc. 139, 9921-9926 (2017)

54. Zhang, Q., Tsai, C. Y., Li, L. J. \& Liaw, D. J. Colorless-to-colorful switching electrochromic polyimides with very high contrast ratio. Nat. Commun. 10, 1239 (2019)

55. Hwang, E. et al. An electrolyte-free flexible electrochromic device using electrostatically strong graphene quantum dot-viologen nanocomposites. Adv. Mater. 26, 5129-5136 (2014).

56. Cao, S., Zhang, S., Zhang, T. \& Lee, J. Y. Fluoride-assisted synthesis of plasmonic colloidal Ta-doped $\mathrm{TiO}_{2}$ nanocrystals for near-infrared and visiblelight selective electrochromic modulation. Chem. Mater. 30, 4838-4846 (2018).

57. Macher, S. et al. New roll-to-roll processable PEDOT-based polymer with colorless bleached state for flexible electrochromic devices. Adv. Funct. Mater. 30, 1906254 (2020). 
58. Zhang, S. et al. Preparation, characterization, and electrochromic properties of nanocellulose-based polyaniline nanocomposite films. ACS Appl. Mater. Inter. 9, 16426-16434 (2017).

59. Li, H., Firby, C. J. \& Elezzabi, A. Y. Rechargeable aqueous hybrid $\mathrm{Zn}^{2+} / \mathrm{Al}^{3+}$ electrochromic batteries. Joule 3, 2268-2278 (2019).

60. Lee, S. H. et al. Electrochromic coloration efficiency of a- $\mathrm{WO}_{3}-\mathrm{y}$ thin films as a function of oxygen deficiency. Appl. Phys. Lett. 75, 1541-1543 (1999).

61. Rui, X. H., Ding, N., Liu, J., Li, C. \& Chen, C. H. Analysis of the chemical diffusion coefficient of lithium ions in $\mathrm{Li}_{3} \mathrm{~V}_{2}\left(\mathrm{PO}_{4}\right)_{3}$ cathode material. Electrochim. Acta 55, 2384-2390 (2010).

62. Pehlivan, E., Niklasson, G. A., Granqvist, C. G. \& Georén, P. Ageing of electrochromic $\mathrm{WO}_{3}$ coatings characterized by electrochemical impedance spectroscopy. Phys. Status Solidi A 207, 1772-1776 (2010).

63. Tang, S. B., Lai, M. O. \& Lu, L. Study on $\mathrm{Li}^{+}$-ion diffusion in nano-crystalline $\mathrm{LiMn}_{2} \mathrm{O}_{4}$ thin film cathode grown by pulsed laser deposition using CV, EIS and PITT techniques. Mater. Chem. Phys. 111, 149-153 (2008).

\section{Acknowledgements}

H.W. and R.L. acknowledge the financial support of the Natural Science Foundation of China (Grant No.51972054) and Fundamental Research Funds for the Central Universities (18D110308). X.L., J.C., T.L., and T.P. acknowledge the support from Semiconductor Research Corporation (SRC). X.L., J.C., and T.L. also acknowledge the support from the Department of Energy under Award No. DE-SC0021064. X.L. acknowledge the membership of the Photonics Centers at Boston University. R.L. acknowledges the support of Graduate Student Innovation Fund of Donghua University (CUSF-DH-D-2019002).

\section{Author contributions}

R.L. and X.M. performed most of experiments. R.L., X.M., X.Z., and L.W. prepared the samples, J.L., J.C., H.G., and T.L. characterized the samples. G.W., C.H., and Y.L. analyzed the data, Q.Z., Y.Li, Y.L., H.W., T.P., and X.L. designed experiments. All authors discussed the results and commented on the manuscript.

\section{Competing interests}

The authors declare no competing interests.

\section{Additional information}

Supplementary information The online version contains supplementary material available at https://doi.org/10.1038/s41467-021-21852-7.

Correspondence and requests for materials should be addressed to Y.L., H.W. or X.L.

Peer review information Nature Communications thanks the anonymous reviewer(s) for their contribution to the peer review of this work. Peer reviewer reports are available.

Reprints and permission information is available at http://www.nature.com/reprints

Publisher's note Springer Nature remains neutral with regard to jurisdictional claims in published maps and institutional affiliations.

(c) (i) Open Access This article is licensed under a Creative Commons Attribution 4.0 International License, which permits use, sharing adaptation, distribution and reproduction in any medium or format, as long as you give appropriate credit to the original author(s) and the source, provide a link to the Creative Commons license, and indicate if changes were made. The images or other third party material in this article are included in the article's Creative Commons license, unless indicated otherwise in a credit line to the material. If material is not included in the article's Creative Commons license and your intended use is not permitted by statutory regulation or exceeds the permitted use, you will need to obtain permission directly from the copyright holder. To view a copy of this license, visit http://creativecommons.org/ licenses/by/4.0/.

(c) The Author(s) 2021 